\title{
Assessing the stability of Pd-exchanged sites in zeolites with the aid of a high throughput quantum chemistry workflow
}

\section{Hassan Aljama}

University of California, Berkeley

Martin Head-Gordon ( $\sim$ mhg@cchem.berkeley.edu )

University of California, Berkeley https://orcid.org/0000-0002-4309-6669

\section{Alexis Bell}

Joint Center for Artificial Photosynthesis, Lawrence Berkeley National Laboratory https://orcid.org/0000-0002-5738-4645

\section{Article}

Keywords: Cation Exchanged-zeolites, Density Functional Theory, High Throughput Screening, NOx Capture

Posted Date: May 7th, 2021

DOl: https://doi.org/10.21203/rs.3.rs-396201/v1

License: (c) (i) This work is licensed under a Creative Commons Attribution 4.0 International License. Read Full License

Version of Record: A version of this preprint was published at Nature Communications on May 25th, 2022. See the published version at https://doi.org/10.1038/s41467-022-29505-z. 


\title{
Assessing the stability of Pd-exchanged sites in zeolites with the aid of a high throughput quantum chemistry workflow
}

\author{
Hassan Aljama, ${ }^{\dagger}$ Martin Head-Gordon, ${ }^{*, \dagger}$ and Alexis T. Bell ${ }^{*, \dagger}$ \\ $\dagger$ Department of Chemical and Biomolecular Engineering, University of California, \\ Berkeley, California \\ $\ddagger$ Department of Chemistry, University of California, Berkeley, California \\ E-mail: mhg@cchem.berkeley.edu; alexbell@berkeley.edu
}

\begin{abstract}
Cation exchanged-zeolites are functional materials with a wide range of applications from catalysis to sorbents. They present a challenge for computational studies using density functional theory due to the numerous possible active sites. From Al configuration, to placement of extra framework cation(s), to potentially different oxidation states of the cation, accounting for all these possibilities is not trivial. To make the number of calculations more tractable, most studies focus on a few active sites. We attempt to go beyond these limitations by implementing a workflow for a high throughput screening, designed to systematize the problem and exhaustively search for feasible active sites. We use Pd-exchanged CHA and BEA to illustrate the approach. After conducting thousands of individual calculations, we identify the sites most favorable for the $\mathrm{Pd}$ cation and discuss the results in detail. The high throughput screening identifies many energetically favorable sites that are non-trivial. Lastly, we employ these results to examine $\mathrm{NO}$ adsorption in $\mathrm{Pd}$-exchanged $\mathrm{CHA}$, which is a promising
\end{abstract}


passive $\mathrm{NO}_{x}$ adsorbent (PNA) during the cold start of automobiles. The results shed light on critical active sites for NOx capture that were not previously studied.

\section{Introduction}

Zeolites are microporous aluminosilicates composed of corner-sharing $\mathrm{TO}_{4}$ tetrahedra $(\mathrm{T}=$ $\mathrm{Si}$ or $\mathrm{Al}$ ). Substitution of trivalent $\mathrm{Al}$ for tetravalent $\mathrm{Si}$ creates a charge imbalance that is compensated by a proton or a metal cation. If the charge compensating cation is a proton, the zeolites becomes a strong solid acid that is an effective catalyst for promoting a wide variety of hydrocarbons reaction as well as the synthesis of a broad range of organic compounds. Metal cation-exchanged zeolites can also serve as adsorbents and catalysts [1-5].

In recent years, considerable insights into zeolite catalyzed reactions have come from the application of quantum chemical analyses of the free energy and enthalpy landscapes governing the progress of chemical reactions $[6,7]$. A significant challenge for such studies is selection of the structure of the active site. To appreciate the issue, we must first recall that there are over 200 known zeolites structures, many of which have $\mathrm{T}$ sites occupied by Si and $\mathrm{Al}$ having symmetries differing from one another. Each of the charge-exchange sites is associated with a framework $\mathrm{Al}$ atom, but the distribution of $\mathrm{Al}$ is generally not known and is thought to be controlled by the kinetics of zeolite synthesis. A further complication is that the charge-exchange site involves an $\mathrm{Al}$ atom bonded to four oxygen atoms, any one of which can accommodate the proton. Further complexity arises when extra-framework metal cations replace protons. Monovalent cations are usually large enough that they bridge two framework oxygen atoms, while bivalent cations can interact with two or three Al sites simultaneously.

It is, therefore, evident that the selection of a representative cation site is challenging and that full exploration of the chemistry on all possible sites is computationally formidable because of cost. For these reasons, many higher level theoretical studies of zeolite-catalyzed 
reactions [8-11] using density functional theory (DFT) have chosen to focus on a few active sites selected on the basis of limited experimental evidence and/or physical intuition. While this choice leads to a more tractable set of calculations, the downside is that potentially important active sites might be missed because they are difficult to identify experimentally or are not physically intuitive. Indeed, growing numbers of DFT studies have progressed from studying single T-sites[12, 13] to address greater complexity[14, 15].

With this trend in mind, the objective of this work is to present and apply a DFTbased computational framework to identify the energetically most favorable adsorption sites (cation or proton) on any zeolite using a systematic high-throughput approach. The underlying calculations employ a hybrid quantum mechanics/molecular mechanics (QM/MM) models $[16,17]$ to capture extended environment around each active site, and high quality DFT[18] to attain acceptable accuracy. Our approach starts by evaluating the possible zeolite structures that arise for different $\mathrm{Si} / \mathrm{Al}$ ratios, then searching for energetically favorable cation/proton(s) adsorption sites for each structure using a lower level of theory (e.g. smaller basis set and cheaper functional) as a filter. The most favorable sites are then evaluated at a higher level of theory. We note that while there are previous high throughput approaches in zeolites, they were largely focused on grand canonical Monte Carlo (GCMC) simulations [19-23].

To illustrate our approach, we use the challenging example of the siting of extraframework Pd ions in Al-doped chabazite (CHA) and beta (BEA). Pd-CHA and Pd-BEA were chosen because they are good candidates for passive NO adsorbers (PNAs) that can be used to trap the emissions of NO from automobile exhaust during cold startup and before the three-way catalytic converter becomes effective [24-26]. The speciation of $\mathrm{Pd}$ in these materials is recognized as a challenging, and still controversial problem [27, 28]. We limit our discussion to the following $\mathrm{Pd}$ species: $\mathrm{Pd}^{+}$associated with isolated charge-exchange sites, $\mathrm{Pd}^{+} \mathrm{H}^{+}$pairs associated with two charge-exchange sites involving next nearest neighbor $(\mathrm{NNN})$ or next-next nearest neighbor $(\mathrm{NNNN})$ pairs of $\mathrm{Al}$ atoms, and $\mathrm{Pd}^{+2}$ associated 
with two charge-exchange sites also involving NNN or NNNN Al pairs. The goal is to provide a methodology that is easily applicable and transferable to any adsorption/catalysis problem with any zeolite, thereby shifting the focus of zeolite studies from a limited number of specific sites to a more systematic approach and allowing a more exhaustive exploration of the descriptor space. After establishing a large set of feasible charge exchange sites for Pd in CHA and BEA, we conclude by assessing the performance of the sites for NO adsorption on $\mathrm{Pd}-\mathrm{CHA}$, with some interesting results.

\section{High Throughput Approach}

Figure 1 shows the workflow for the high throughput approach to determine which chargeexchange sites are most favorable for accommodating the charge-compensating cation and/or proton. Briefly, $\mathrm{Al}$ atom(s) are first introduced at different tetrahedral sites in the bare $\mathrm{Si}_{x} \mathrm{O}_{y}$ zeolite, generating structures with unique (i.e. distinguishable) Al positions. For each unique $\mathrm{Al}$ arrangement, distinctions are made between atoms in the QM region, which are expected to be active in the adsorption process, and the surrounding atoms in the MM region. To determine the most energetically favorable location for accommodating the extra framework cation, potential cation-exchanged sites are first enumerated and then surveyed by QM/MM calculations at the GGA level of theory, followed by further evaluation of the top 5 most stable sites at the hGGA level of theory. Lastly, results for all structures are compared to determine the structures where $\mathrm{Al}$ position(s) yield the most stable charge-exchange site. Each step is discussed in detail in the next few sections.

\section{Distinguishable Al locations}

The first step of the approach (Figure 1) is determining the set of distinguishable Al sites in the zeolite structure. Univalent structures could be easily generated by replacing each unique $\mathrm{Si}$ T-atom in the zeolite by an $\mathrm{Al}$ atom. However, generating $\mathrm{Al}$ pairs is not trivial 


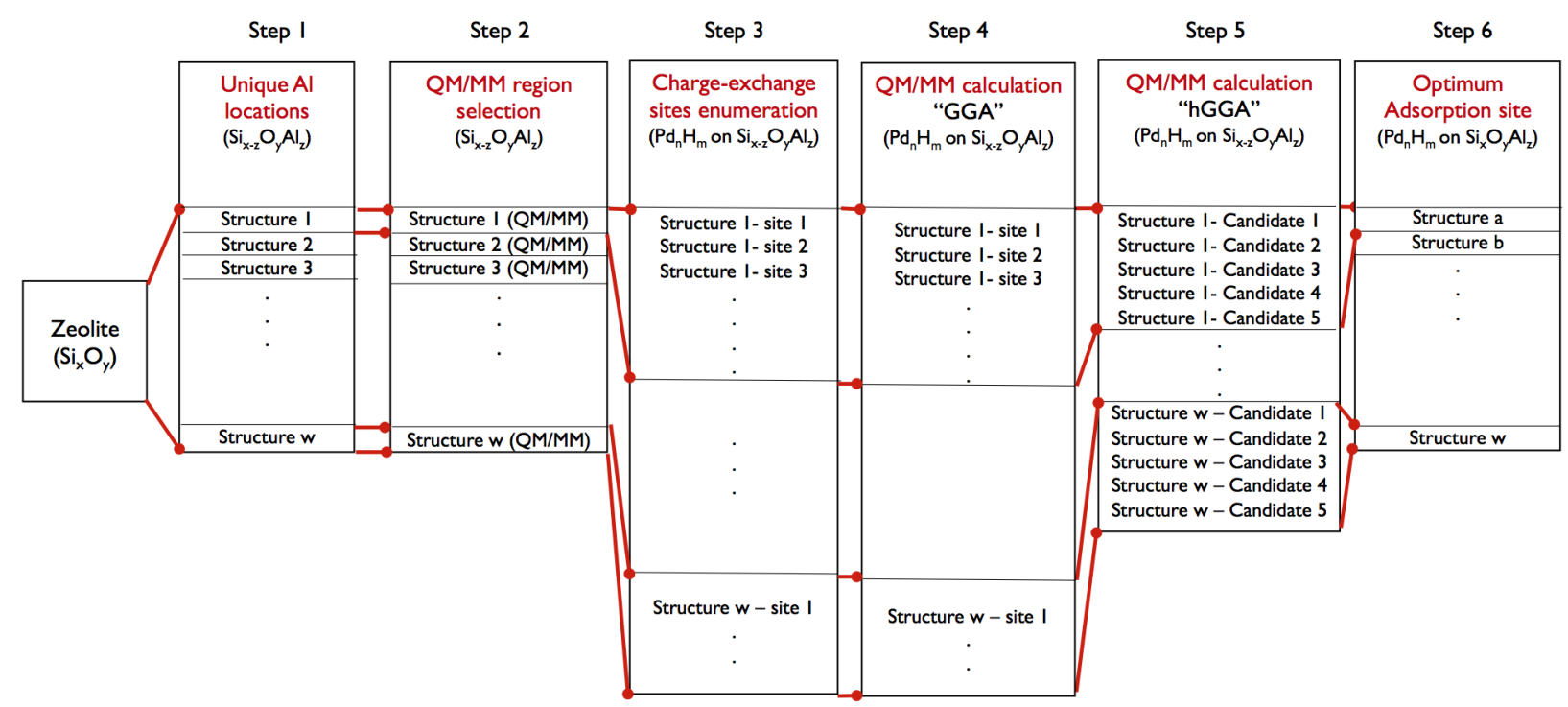

Figure 1: Workflow of the high throughput approach used in this work. $\operatorname{Pd}_{n} \mathrm{H}_{n}(n=0,1$ or 2 and $m=0,1$ or 2) is used as an illustration. Starting with the zeolite material, structures are generated by identifying the unique $\mathrm{Al}$ position(s) in step 1 (generating structures from 1 to $\mathrm{w}$ ), followed by identifying atoms in the QM and MM region for each structure in step 2. In step 3, possible charge-exchange sites are enumerated and then further evaluated in step 4 using QM/MM calculations at the GGA level. The 5 most favorable exchange sites from step 4 for each unique Al position are further evaluated at the hGGA level of theory in step 5. Finally, all structures from step 5 are ordered based on their energy stability, yielding the most energetically favorable sites for the exchange in the zeolite in step 6 
due to the 3D structure of zeolites. While this can be done manually for CHA, since it only has one unique T-site, it is more challenging to do for BEA, which has 9 T-sites. Hence, we developed an automated method to generate all possible $\mathrm{Al}$ pairs. We focused in this work on pairs in the NNN (where the two framework $\mathrm{Al}$ are separated by a single $\mathrm{Si}$ atom) and the NNNN (where the two framework $\mathrm{Al}$ are separated by two Si atoms). Al pairs in nearest neighbor (NN) position were avoided in order to satisfy the Loewenstein rule [29]. Pairs further apart than NNNN were not considered since Al pairs further away should behave as isolated $\mathrm{Al}$ atoms. We note that this approach is easily applicable to any zeolite material and can be extended beyond NNNN pairs.

Our approach uses a molecular graph that identifies the connectivity of each atom in the cluster $[30,31]$ (visually illustrated in Figure 2). Each Al pair structure is generated by first identifying a unique T-site $\left(\mathrm{Si}^{T-a t o m}\right)$. Based on the connectivity of the $\mathrm{Si}^{T-a t o m}$, its NN Si atoms are identified $\left(\mathrm{Si}^{N N}\right)$. The $\mathrm{Si}$ atoms in NNN $\left(\mathrm{Si}^{N N N}\right)$ are identified by finding the next neighbor of $\mathrm{Si}^{N N}$ (excluding the original $\mathrm{Si}^{T-a t o m}$ and $\mathrm{Si}^{N N}$ ). Each NNN Al pairs are generated by replacing $\mathrm{Si}^{T-a t o m}$ and one of the $\mathrm{Si}^{N N N}$ with $\mathrm{Al}$ atoms. For the NNNN Al pairs, the next neighbor of the $\mathrm{Si}^{N N N}$ atom are identified $\left(\mathrm{Si}^{N N N N}\right)$ (excluding $\mathrm{Si}^{T-a t o m}$, $\mathrm{Si}^{N N}$ and $\left.\mathrm{Si}^{N N N}\right)$. Similarly, $\mathrm{Si}^{T-a t o m}$ and each one of the $\mathrm{Si}^{N N N N}$ atoms are then replaced with $\mathrm{Al}$ atoms to generate the $\mathrm{NNNN} \mathrm{Al} \mathrm{pairs.} \mathrm{In} \mathrm{this} \mathrm{manuscript,} \mathrm{each} \mathrm{structure} \mathrm{with} \mathrm{a}$ unique $\mathrm{Al}$ location is identified by a unique index after the zeolite name (e.g. CHA-13) (full details on the xyz coordinates for the structures are available in the Supporting Information (SI)).

Since the procedure described above can produce duplicate structures, we relied on calculating the nuclear repulsion energy of all generated pairs to eliminate duplicates. The method was verified using a BEA unit cell (which contains 36 T-atoms) and generating 36 different structures by replacing each $\mathrm{Si}$ T-atom with an $\mathrm{Al}$ atom. By using the nuclear repulsion energy, we were able to recover the 9 unique T-sites. Overall, this results in 26 and 212 unique structures for CHA and BEA, respectively. In order to make the number 

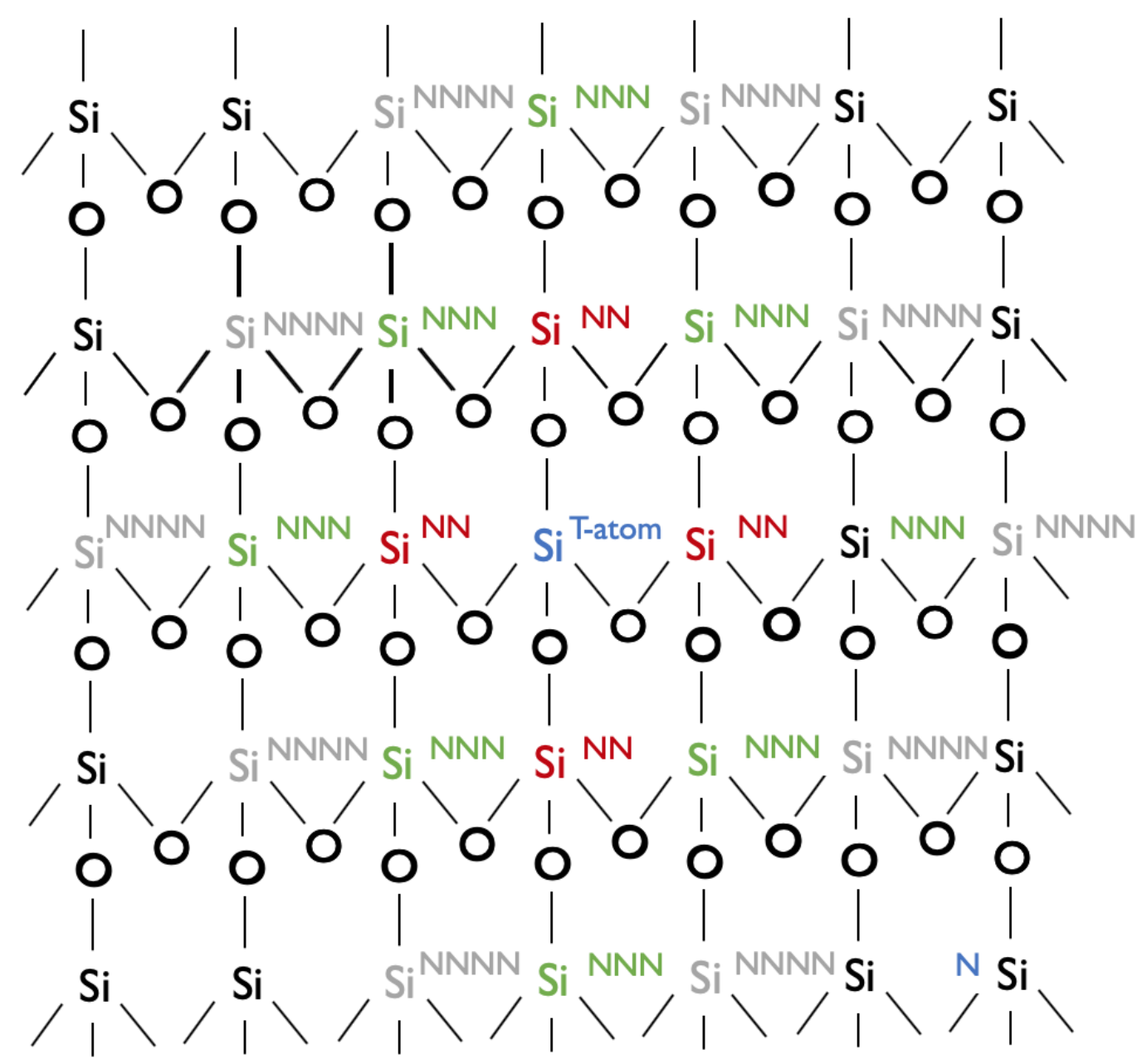

Figure 2: Visual illustration of atoms positions surrounding the $\mathrm{Si}^{T-a t o m} \cdot \mathrm{Si}^{T-a t o m}$ is replaced with an $\mathrm{Al}$ atom to generate a univalent structure. For divalent structures, $\mathrm{Si}^{N N}, \mathrm{Si}^{N N N}$, and $\mathrm{Si}^{N N N N}$ atoms are identified and then desired structures are generated by replacing either the $\mathrm{Si}^{N N N}$ or $\mathrm{Si}^{N N N N}$ and $\mathrm{Si}^{T-a t o m}$ atom with $\mathrm{Al}$ atoms 
of calculations more tractable, we further reduced the number of candidates by eliminating structures that share the same connectivity (i.e., the $\mathrm{Al}$ atoms in structures share the same types of $n$-membered-ring $(n$-MR)). Although in those cases structures are not exactly the same, they are structurally very similar (Figure S1). We also did not evaluate structures for BEA for which $\mathrm{Al}$ pairs do not share the same MR and are on opposite sides of the open cage (Figure S2). This reduced the final numbers to 82 structures for BEA and 12 structures for CHA.

\section{Selection of the QM and MM regions}

The second part of the workflow (Figure 1) defines the atoms that comprise the QM region and the surrounding MM atoms in the cluster. Appropriate choice of the QM region is critical for the QM/MM calculations since the number of atoms must be sufficient to ensure the calculations converge, but not too large in order to avoid significant computational cost. For structures with an isolated $\mathrm{Al}$ atom, the $\mathrm{Si}$ and $\mathrm{O}$ atoms that create a 4,5 or $6 \mathrm{MR}$ with the $\mathrm{Al}$ atom are included in the $\mathrm{QM}$ atoms. If the structure contains an $\mathrm{Al}$ pair, and if the two pairs form a 4,5,6,7 or $8 \mathrm{MR}$, we include all $\mathrm{Si}$ and $\mathrm{O}$ atoms that are part of the $n$-MR. Also, for those structures, we include $\mathrm{Si}$ and $\mathrm{O}$ atoms that are part of a 4 or $5 \mathrm{MR}$ with either of the two $\mathrm{Al}$ atoms. Atoms comprising a $\mathrm{MR}$ are identified following the procedure described in Figure S3. The QM region includes on average 54 atoms, excluding hydrogen atoms used to terminate the Si atoms. The QM regions used here are larger than used in

previous work $[11,32-35]$ and we found it to be more than sufficient for the calculations to converge (Figure S4). Finally, for the calculations of NO adsorption in Pd-CHA, the number of QM atoms was extended as needed to account for potential interactions of NO with other $\mathrm{Si} / \mathrm{O}$ atoms in the framework. 


\section{Enumeration of charge-exchange sites}

For each structure with a unique $\mathrm{Al}$ arrangement, we survey the energy landscape by placing the adsorbate(s) at multiple initial positions near each oxygen atom neighboring $\mathrm{Al}$ atom(s), as shown in Figure S5. For structures with an isolated $\mathrm{Al}$ atom, this requires only 4 calculations for either $\mathrm{Pd}^{+}$or $\mathrm{H}^{+}$. For structures with an $\mathrm{Al}$ pair, finding the optimum position of a $\mathrm{Pd}^{+2}$ requires 8 calculations per structure, and finding the optimum position for $\mathrm{H}^{+} \mathrm{H}^{+}$ requires 16 total calculations. The most complicated case is for a $\mathrm{Pd}^{+} \mathrm{H}^{+}$site near an $\mathrm{Al}$ pair, where in addition to surveying for $\mathrm{Pd}^{+}$charge-exchange site, a proton must be present near the opposite $\mathrm{Al}$ atom to compensate for the missing charge. This situation requires a total of 32 calculations per structure. We note that these numbers reflect the maximum number of calculations attempted. For some very unfavorable initial positions, the calculations did not converge. This is mostly limited to the GGA level search and happens in less than $10 \%$ of the total calculations (for the most part, this is due to placing Pd at the center of a 4MR). The extended number of initial positions in the scheme inevitably leads to some poor initial conditions. All generated structures and optimized geometries are available in the SI.

\section{Survey of charge-exchange sites}

The major part of the computational cost in the workflow (Figure 1) is associated with searching for the global minimum energy of the charge-exchange site, steps 4 and 5 . For zeolites with multiple T-sites, the number of calculations is significant. Carrying out all the calculations at the range-separated hybrid functional level of theory is intractable; however, it has been shown previously that this level of theory is needed to reach close agreement with experimental values [36]. Accordingly, we first use the B97-D3 exchange functional (which is at the GGA level) as a filter to determine the 5 most favorable exchange positions for the cation/proton(s) per each unique $\mathrm{Al}$ arrangement. For those 5 candidates, further calculations are done at the range-separated hybrid level using the $\omega$ B97X-D exchange functional to determine the most energetically favorable position of the cations per each unique $\mathrm{Al}$ 
arrangement. We tested this approach on a number of structures by comparing the results between doing the full calculations using only $\omega$ B97X-D to the approach described earlier. We found this approach to yield virtually the same results with significant reduction in computational cost (Table S1).

In order to compare the stability of the Pd cation at different cation-exchanged sites, we calculated the energy of reaction $\left(\Delta E_{\text {form }}\right)$ for the following two reactions:

$$
\begin{gathered}
\mathrm{Pd}_{(g)}+\mathrm{H}^{+} \mathrm{Z}^{-}+\frac{1}{4} \mathrm{O}_{2(g)} \rightarrow \mathrm{Pd}^{+} \mathrm{Z}^{-}+\frac{1}{2} \mathrm{H}_{2} \mathrm{O}_{(g)} \\
\mathrm{Pd}_{(g)}+\mathrm{H}^{+} \mathrm{H}^{+} \mathrm{Z}^{-2}+\frac{x}{4} \mathrm{O}_{2(g)} \rightarrow \mathrm{Pd}^{+x} \mathrm{H}^{+}{ }_{2-x} \mathrm{Z}^{-2}+\frac{x}{2} \mathrm{H}_{2} \mathrm{O}_{(g)}
\end{gathered}
$$

Equation 1 is used for an isolated $\mathrm{Al}$ zeolite and equation 2 for structures with an $\mathrm{Al}$ pair. $(x)$ is the oxidation state of $\mathrm{Pd}$ (either 1 or 2$),\left(\mathrm{Pd}_{(g)}\right)$ is a gas phase $\mathrm{Pd}$ atom, $\left(\mathrm{H}^{+}\right)$ is the compensating proton, $(\mathrm{Z})$ is the charged zeolite framework, $\left(\mathrm{H}_{2} \mathrm{O}_{(g)}\right)$ and $\left(\mathrm{O}_{2(g)}\right)$ are water and oxygen in the gas phase, and $\left(\mathrm{Pd}^{+x}\right)$ is the $\mathrm{Pd}$ adsorbed in the zeolite framework. Equations 1 and 2 allow comparing the relative stability of sites with different $\mathrm{Al}$ configurations and oxidation states by using a consistent reference. The equations also rely on using a Brønsted site as a reference. This eliminates the impact of the thermodynamics of Al placement in the zeolite (which is kinetically driven during the synthesis of the zeolite [37]). For NO adsorption on Pd-exchanged CHA, we use the following equation to calculate the $\mathrm{NO}$ adsorption energy $\left(\Delta E_{\mathrm{NO}}\right)$ :

$$
\Delta E_{\mathrm{NO}}=E_{\mathrm{Pd} * \mathrm{NO} *}-E_{\mathrm{Pd} *}-E_{\mathrm{NO}_{(g)}}
$$

where $\left(E_{\mathrm{Pd} * \mathrm{NO} *}\right)$ is the total energy of $\mathrm{NO}$ adsorbed on the Pd-exchanged zeolite in the DFT calculation, $\left(E_{\mathrm{Pd} *}\right)$ is the total energy of the $\mathrm{Pd}$ adsorbed on the zeolite framework and $\left(E_{\mathrm{NO}_{(g)}}\right)$ is the total energy of $\mathrm{NO}$ in the gas phase. $\mathrm{Pd} *$ refers to either $\mathrm{Pd}^{+}, \mathrm{Pd}^{+} \mathrm{H}^{+}$, or $\mathrm{Pd}^{+2}$. 


\section{Results and Discussion}

Results of $\mathrm{Pd}$ cation siting in CHA are discussed first followed by a discussion of cationexchanged BEA. A comparison between the two types of zeolites is then made. Finally, we apply our results to NO adsorption on Pd-exchanged CHA.

\section{Pd-exchanged CHA}

We start by reporting our results for the location of $\mathrm{Pd}$ cations exchanged into CHA [27, 28]. CHA has a single T-site, which limits the number of unique Al pairs. As mentioned previously, equations 1 and 2 are used to evaluate the stability of the sites. This requires, for each unique $\mathrm{Al}$ arrangement, finding the minimum energy of the compensating protons and the Pd cation. An example of the search results for the optimum proton location (based on sampling different initial positions for a given Al siting), is shown in Figure S6. Some locations can be more favorable than others by as much as $1 \mathrm{eV}$. Based on an examination of the stability of the 12 different $\mathrm{Al}$ arrangements in $\mathrm{CHA}$, we do not find a clear indication of why certain positions stabilize protons more than others. One descriptor we find useful is the distance between the oxygen atoms where the protons adsorb $\left(\mathrm{d}_{O-O}\right)$ (Figure $\left.\mathrm{S} 7\right)$. If the oxygen atoms are too close or too far (relative to Al-Al distance), the associated 2 proton configuration is not favorable. Intermediate distance almost always yields the most favorable arrangement. This descriptor can reduce the number of required calculations; however, it is not a substitute for performing the search through an approach such as the high throughput screening employed here, especially since many candidates have similar values of $\mathrm{d}_{\mathrm{O}-\mathrm{O}}$.

In addition, sample search results for the global minimum of $\mathrm{Pd}^{+} \mathrm{H}^{+}$exchange are shown in Figure S8. As for the proton case discussed above, there is a large variance of the results depending on the initial position of the $\mathrm{Pd}$ cation and the proton. It is important to also note that the relative energy is sensitive to the proton position. For example, $\mathrm{CHA}-3-\mathrm{Pd}^{+} \mathrm{H}^{+}-17$ and $\mathrm{CHA}-3-\mathrm{Pd}^{+} \mathrm{H}^{+}-21$ both have the $\mathrm{Pd}$ at the center of the $6 \mathrm{MR}$; however, the latter is 0.4 
$\mathrm{eV}$ less stable due to the proton occupying a different location (Figure S9).

A summary of the energies of $\mathrm{Pd}^{+} \mathrm{H}^{+}$and $\mathrm{Pd}^{+2}$ in CHA, comparing unique $\mathrm{Al}$ positions, is given in Figures 3 and 4, respectively. In both cases, the stability of the Pd cation is heavily dependent on the $\mathrm{Al}$ positions, with energies varying by as much as several $\mathrm{eV}$. The range of energies in $\mathrm{Pd}^{+} \mathrm{H}^{+}$is much more closely spaced $(<0.8 \mathrm{eV})$ compared to $\mathrm{Pd}^{+2}$ (around $3 \mathrm{eV}$ ). Al pairs in the 6MR arrangements, especially in the NNNN position, provide the most favorable host for the Pd cation, in which case the Pd resides at the center of the 6MR (Figure 5a and b and Figure S10a and b). This finding is consistent with other recent studies $[27,28]$. This geometry provides the most number of oxygen atoms in close proximity to the cation, but not too close. Surprisingly, the Pd cation is then most stable either at the isolated site or when the two $\mathrm{Al}$ pairs do not share the same ring. In these cases, the $\mathrm{Pd}$ cation mostly resides at the center of the $6 \mathrm{MR}$ (Figure S10c-f). For both $\mathrm{Pd}^{+} \mathrm{H}^{+}$and $\mathrm{Pd}^{+2}$, $\mathrm{Al}$ pairs in the $8 \mathrm{MR}$ and $4 \mathrm{MR}$ provide unfavorable arrangements, especially for the latter. In the $8 \mathrm{MR}$ (Figure $\mathrm{S} 10 \mathrm{~g}$ and $\mathrm{h}$ ), unlike the $6 \mathrm{MR}$, the two $\mathrm{Al}$ atoms are farther apart and there is a lack of neighboring $\mathrm{Si} / \mathrm{O}$ atoms to provide orbital overlap to stabilize the cation. In the case of the $4 \mathrm{MR}$, the atoms are too closely spaced.

Despite some attempts to do, we were not able to find a simple descriptor related to $\Delta E_{\text {form }}$ (e.g. $\mathrm{Al}-\mathrm{Al}$ distance and $\mathrm{Si} / \mathrm{O}$ atoms in close proximity) for the data contained in Figures 3 and 4. For $\mathrm{Pd}^{+} \mathrm{H}^{+}$, in almost all calculations, a minimum distance of $4 \AA$ separates the Pd cation and the proton in the optimized structure (Figure S11). This indicates repulsive interaction between the two cations at shorter distances.

Comparing $\Delta E_{\text {form }}$ between $\mathrm{Pd}^{+} \mathrm{H}^{+}$and $\mathrm{Pd}^{+2}$ on CHA shows all $\mathrm{Al}$ pairs arrangements are more favorable to $\mathrm{Pd}^{+} \mathrm{H}^{+}$compared to $\mathrm{Pd}^{+2}$, with the exceptions of $\mathrm{Al}$ pairs in $6 \mathrm{MR}$. This has implications for the adsorption of guest molecules, as will be discussed later on. 


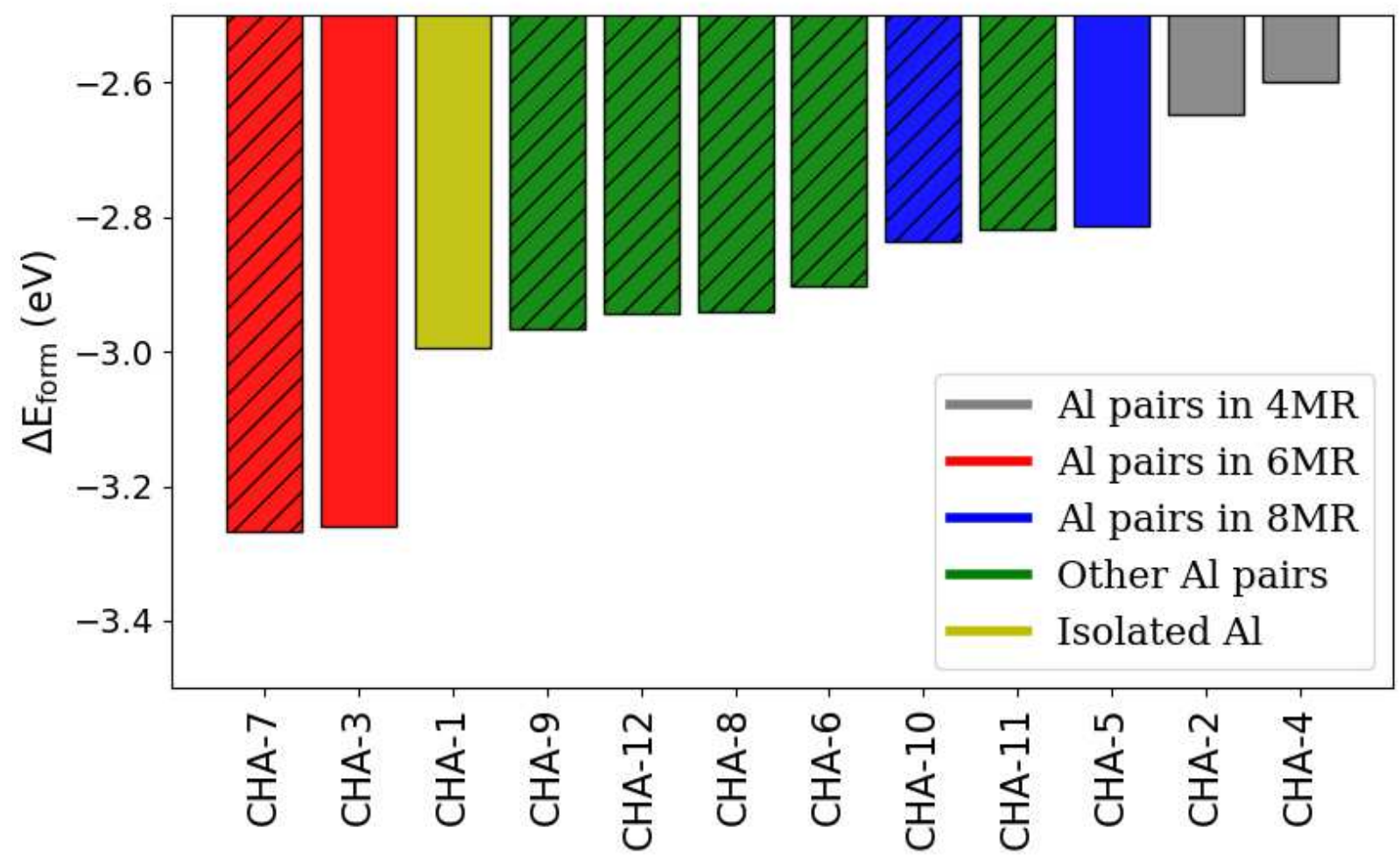

Figure 3: Formation Energy of $\mathrm{Pd}^{+} \mathrm{H}^{+}$on CHA. Each bar represents unique Al location(s). The color coding refers to the type of $\mathrm{Al}$ pairs or isolated $\mathrm{Al}$ in the zeolite matrix. Solid bars refer to $\mathrm{Al}$ pairs in an $\mathrm{NNN}$ configuration or the isolated site and striped bars refer to the NNNN configuration. 


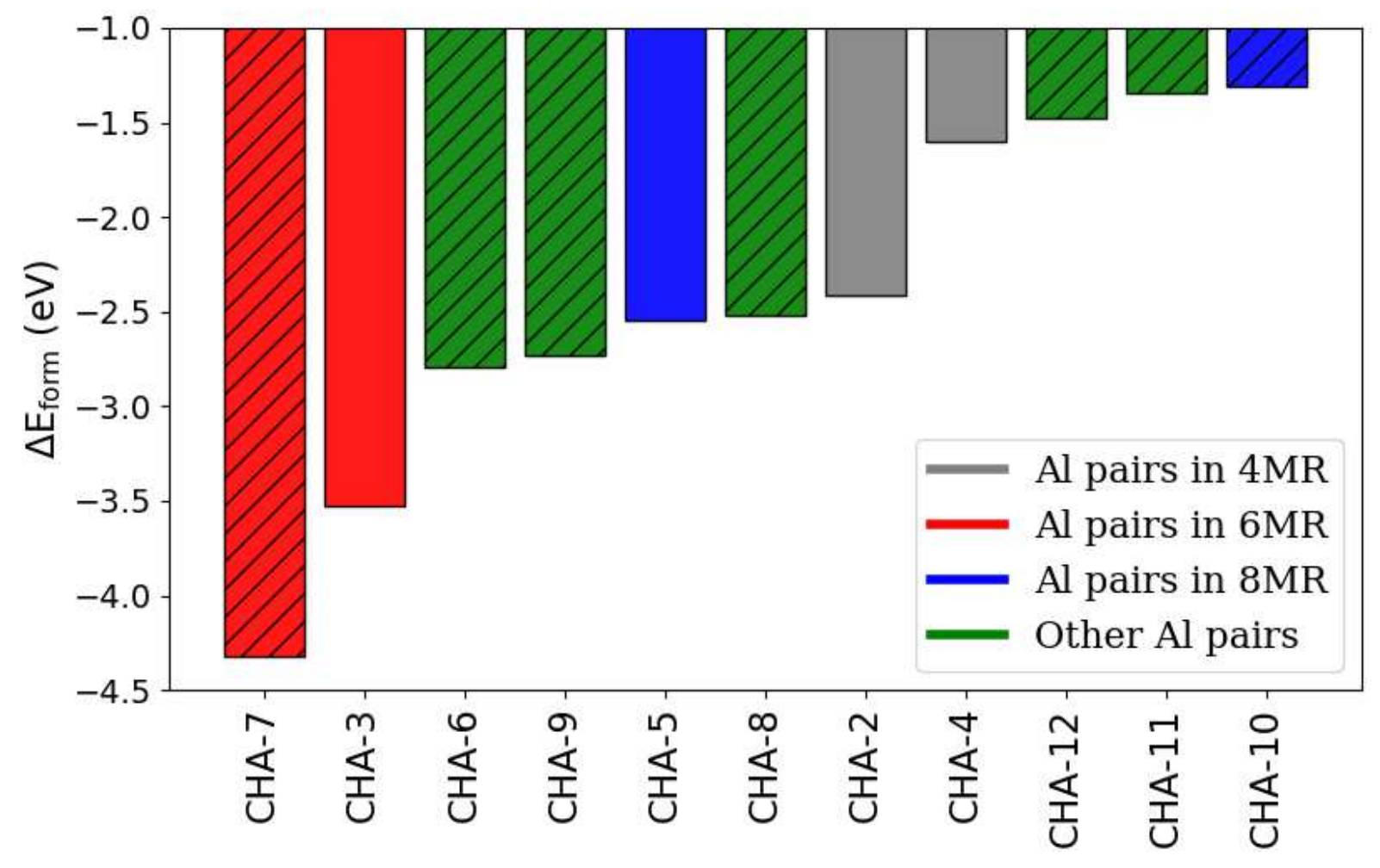

Figure 4: Formation energy of $\mathrm{Pd}^{+2}$ on CHA. Each bar represents unique $\mathrm{Al}$ location(s). Color coding refers to the type of $\mathrm{Al}$ pairs or isolated $\mathrm{Al}$ in the zeolite matrix. Solid bars refer to Al pairs in NNN configuration and striped bars refer to NNNN configuration. The two most stable sites (CHA-7 and CHA-3) are illustrated in Figure 5. 
a. $\mathrm{Pd}^{+2}$ on CHA-7

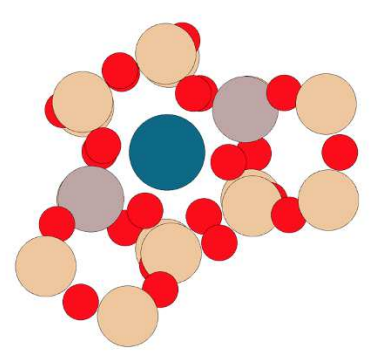

e. $\mathrm{Pd}^{+2}$ on $\mathrm{BEA}-45$

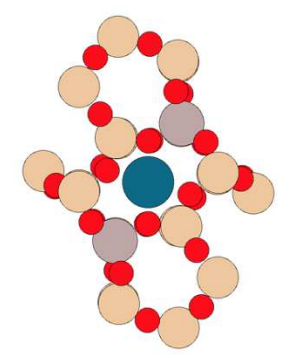

b. $\mathrm{Pd}^{+2}$ on $\mathrm{CHA}-3$
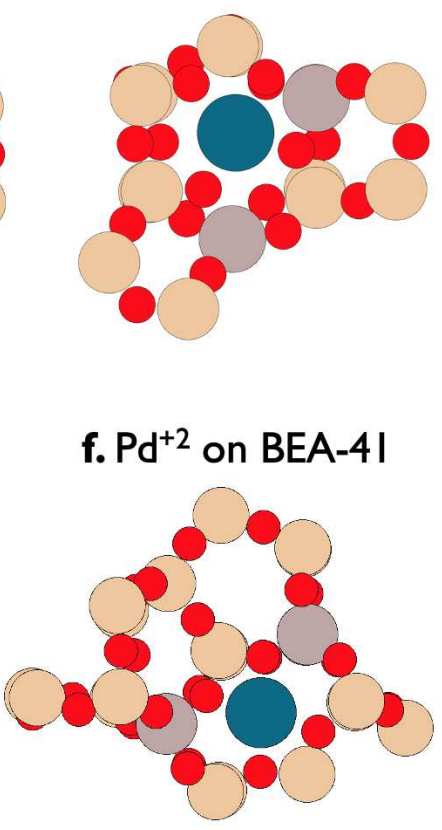

c. $\mathrm{Pd}^{+2}$ on BEA-65

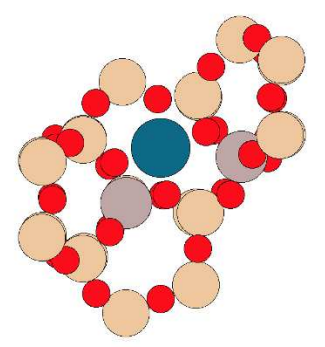

g. $\mathrm{Pd}^{+} \mathrm{H}^{+}$on $\mathrm{BEA}-65$

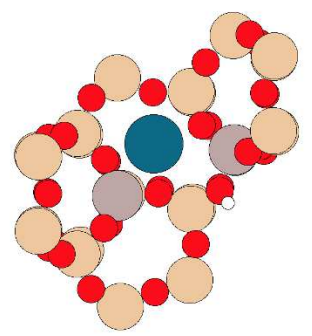

d. $\mathrm{Pd}^{+2}$ on $\mathrm{BEA}-80$

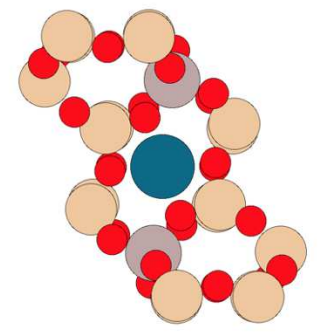

Figure 5: QM atoms of the optimized calculations. Color coding: red=Oxygen, white $=$ Hydrogen, blue $=$ Palladium and beige $=$ Silicon

\section{Pd-exchanged BEA}

BEA has a more diverse set of rings (4,5,6 and 12), 9 T-sites, and is denser than CHA. This makes it more challenging and nontrivial to determine the favorable sites for the cations. Similar to CHA, we carried out calculations for $\mathrm{Pd}^{+}, \mathrm{Pd}^{+} \mathrm{H}^{+}$, and $\mathrm{Pd}^{+2}$ charge-exchanged into BEA using the approach shown in Figure 1. Figure 6 summarizes the results for $\mathrm{Pd}^{+2}$ in BEA. It is noticeable that the four most energetically favorable structures all have Al pairs in 6MR (images of the QM atoms are shown in Figure 5c-f). The four structures are separated by $0.15-0.6 \mathrm{eV}$. Structure BEA-65 (Figure 5c), the most favorable energetically, has Al pairs in a $6 \mathrm{MR}$ in NNN configuration. The Pd cation resides at the center of the $6 \mathrm{MR}$ in close proximity to 4 neighboring oxygen atoms. The three structures closest in energy (BEA-80, BEA-45 and BEA-41) have similar configurations, but differ mainly in Al placements within the $6 \mathrm{MR}$ and the $\mathrm{Si} / \mathrm{O}$ atoms surrounding the $6 \mathrm{MR}$. These four structures are followed by a number of structures where $\mathrm{Al}$ pairs are in a 5MR (e.g. Figure S12a). Those 5MR structures 
are close in energy (separated by less than $0.15 \mathrm{eV}$ ). In all of these cases, the $\mathrm{Pd}$ cation is most stable at the center of the $5 \mathrm{MR}$. Al pairs in 4MR (e.g. BEA-36) are poor hosts for the $\mathrm{Pd}$ cation, similar to what was observed for $\mathrm{CHA}$. For $\mathrm{Al}$ pairs not in a 4,5 or $6 \mathrm{MR}, \Delta \mathrm{E}_{\text {form }}$ is considerably lower. The most stable structure for those cases (BEA-55, Figure S12b) is $1.2 \mathrm{eV}$ weaker compared to the most stable structure. This reinforces the results observed in CHA (Figure 4) where Al pairs in the same $n$-MR allow for additional stability of the cation. This likely stems from having neighboring oxygen atoms in positions favorable for orbital overlap with the $\mathrm{Pd}$ cation. However, this observation fails to explain why some of the other structures with $\mathrm{Al}$ pairs in a $6 \mathrm{MR}$ or $5 \mathrm{MR}$ arrangements (e.g. BEA-62 and BEA-59) have significantly smaller values of $\Delta \mathrm{E}_{\text {form }}$. This subject will be discussed further below.

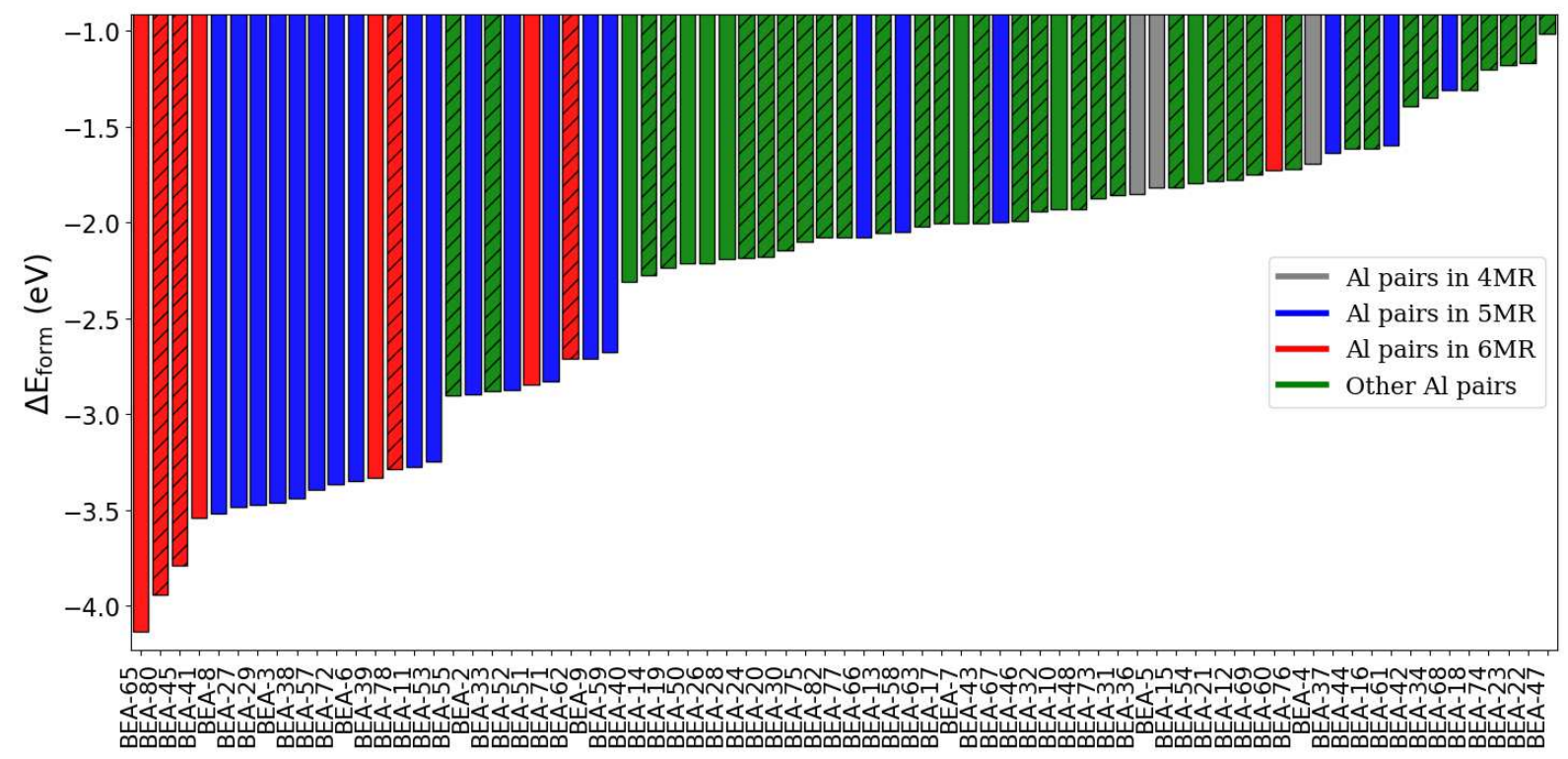

Figure 6: Formation energy of $\mathrm{Pd}^{+2}$ on BEA. Each bar represents unique Al locations. Color coding refers to the type of $\mathrm{Al}$ pairs in the zeolite matrix. Patterned bars refer to $\mathrm{Al}$ pairs in NNNN positions while solid bars refer to Al pairs in NNN positions. The four most stable sites are illustrated in Figure 5.

Figure 7 summarizes the formation energies for $\mathrm{Pd}^{+}$and $\mathrm{Pd}^{+} \mathrm{H}^{+}$on $\mathrm{BEA}$. Structure BEA-65 is the most energetically favorable site in BEA for $\mathrm{Pd}^{+} \mathrm{H}^{+}$. It is the same site that hosts the most stable $\mathrm{Pd}^{+2}$, for which the cation is located at the center of the $6 \mathrm{MR}$ and the $\mathrm{Al}$ pairs are in NNN arrangement (Figure $5 \mathrm{~g}$ ). It is $>0.25 \mathrm{eV}$ more favorable than 
any of the other structures examined. Surprisingly, structures BEA-33 and BEA-55 (Figure $\mathrm{S} 12 \mathrm{c}$ and $\mathrm{d}$ ), in which the $\mathrm{Al}$ pairs are do not share a $5 \mathrm{MR}$ or $6 \mathrm{MR}$, are more stable than the other $\mathrm{Al}$ pairs in $5 \mathrm{MR}$ or $6 \mathrm{MR}$. However, after BEA-65, most of the structures are close in energy (the difference can be $<0.1 \mathrm{eV}$ ). Given DFT errors and the large number of structures close in energies, it is difficult to make a conclusion on the order between many of these structures. Nevertheless, there is a lack of clear distinctions between $\mathrm{Al}$ pairs in the same $n$-MR observed for $\mathrm{Pd}^{+2}$ in $\mathrm{CHA}$ and BEA. Some Al configurations (e.g. BEA-8) can have a high $\Delta E_{\text {form }}$ for $\mathrm{Pd}^{+2}$ but not for $\mathrm{Pd}^{+} \mathrm{H}^{+}$. This indicates that results are not transferable between different oxidation states. It also sheds light on potential importance of sites where $\mathrm{Al}$ pairs do not share a $5 \mathrm{MR}$ or $6 \mathrm{MR}$, a motif that does not generally receive much attention in computational studies, and the role they can play in adsorption/catalysis. In these structures, the presence of a neighboring $\mathrm{Al}$ atom in close proximity can significantly alter the $\Delta E_{\text {form }}$ compared to their respective value for isolated sites (Figure S13).

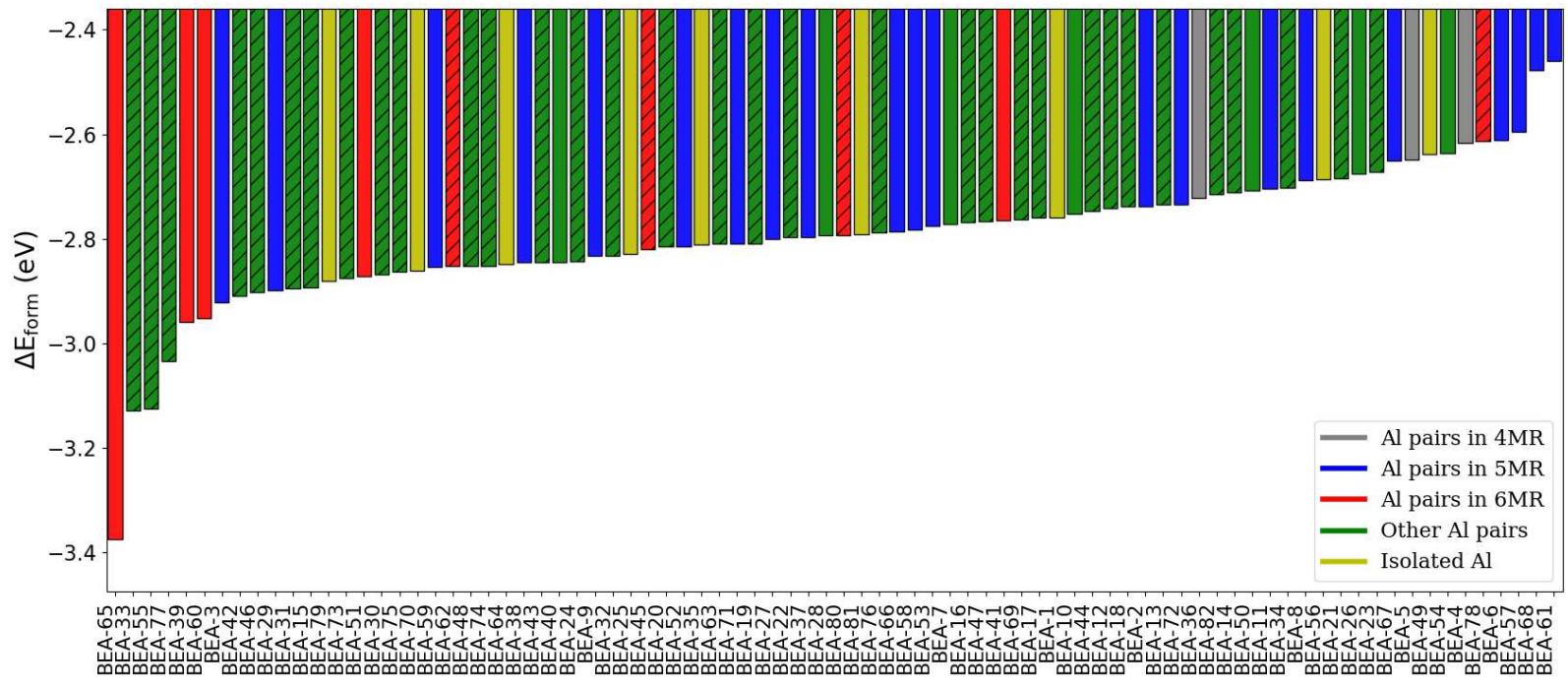

Figure 7: Formation energy of $\mathrm{Pd}^{+}$on BEA. Each bar represents unique Al location(s). Color coding refers to the type of $\mathrm{Al}$ pairs or isolated $\mathrm{Al}$ in the zeolite matrix. In $\mathrm{Al}$ pairs, patterned bars refer to $\mathrm{Al}$ pairs in NNNN positions and solid colors refer to Al pairs in NNN positions. The most stable site (BEA-65) is illustrated in Figure 5.

During the search for the most favorable charge-exchange sites, we found that in some cases the energetically most favorable Pd cation position may not involve situating the cation 
within a single ring, even if the $\mathrm{Al}$ pairs are in the same MR. Examples of this situation are BEA-51, BEA-78, and BEA-52, shown in Figure S14. These positions can be $>0.2 \mathrm{eV}$ more stable than the $\mathrm{Pd}$ at the center of the 6MR. This highlights the importance of the high throughout screening approach, which can find the optimum adsorption location when it is not the most physically intuitive.

Although the energetic order of $\mathrm{Al}$ configurations in BEA does not correlate directly for $\mathrm{Pd}+1$ and +2 oxidation states, we attempted to confirm whether this is true or not for $\mathrm{Co}^{+2}$ cations. We performed a limited number of calculations on $\mathrm{Co}^{+2}$ on $\mathrm{CHA}$ and found a similar trend in terms of favorable $\mathrm{Al}$ pairs (Figure 8). This indicates that the results for one cation in a zeolite matrix are can be transferable to other, chemically similar, cations exchanged into the same zeolite. This finding is important, since the UV-Vis spectrum of $\mathrm{Co}^{2+}$ is used to identify the location of divalent cation in zeolites [38, 39].

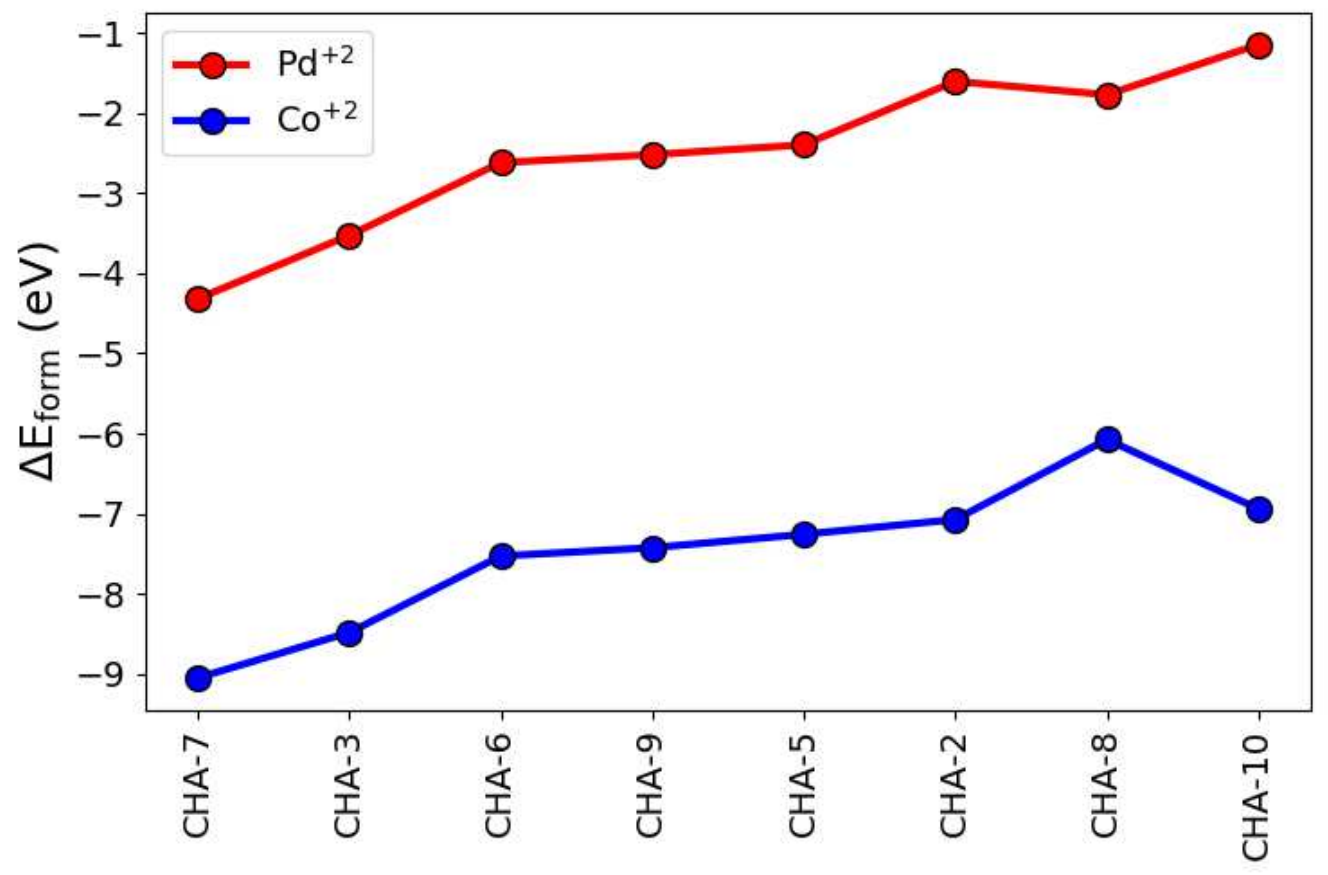

Figure 8: Comparison between favorable $\mathrm{Al}$ pair configurations for $\mathrm{Pd}^{+2}$ and $\mathrm{Co}^{+2}$ 


\section{Comparison between Pd-exchanged CHA and BEA}

In general, there are similarities in Pd-exchanged BEA and CHA. In both cases, the Pd cation (both as a $\mathrm{Pd}^{+2}$ and $\mathrm{Pd}^{+} \mathrm{H}^{+}$) is energetically most favorable in the 6MR. For $\mathrm{Pd}^{+} \mathrm{H}^{+}$ and $\mathrm{Pd}^{+2}$, the site with the highest $\Delta E_{\text {form }}$ has almost identical energy values (around -3.3 $\mathrm{eV}$ and -4.2 , respectively). The $6 \mathrm{MR}$ in BEA is more oval shaped (Figure $5 \mathrm{c}$ ) compared to that of CHA (Figure 5a), placing the oxygen atoms at a closer distance. The four oxygens close to the Pd cation in the $6 \mathrm{MR}$ are on average located $2.0 \AA$ from the Pd in BEA and 2.2 $\AA$ in CHA. This, however, does not seem to impact the formation energy.

\section{NO Adsorption}

The location of Pd cations in CHA and BEA has practical implications for the capability of the zeolite to act as a passive $\mathrm{NO}_{x}$ adsorber (PNA) during the cold start of automobiles. The nature of the oxidation state of the Pd cations and their location in the zeolite continue to be debated in the scientific literature $[27,28,40]$. Here, we attempt to shed some light on the subject based on the results of our high throughput screening. We focus on NO adsorption on $\mathrm{Pd}$-exchanged-CHA, considering $\mathrm{Pd}^{+}, \mathrm{Pd}^{+} \mathrm{H}^{+}$, and $\mathrm{Pd}^{+2}$. Figure 9 shows the correlation results between $\Delta \mathrm{E}_{\mathrm{NO}}$ and $\Delta E_{\text {form }}$. Generally, a weaker $\Delta E_{\text {form }}$ correlates with a stronger NO adsorption energy. Similar to most adsorption processes, the stronger the binding energy of the cation site, the less electron density is available to bind the guest gas specie [41]. Although there appears to be a linear correlation with a low mean absolute error (MAE) (0.1 and $0.22 \mathrm{eV}$ for $\mathrm{NO}$ adsorption on $\mathrm{Pd}^{+} \mathrm{H}^{+}$and $\mathrm{Pd}^{+2}$, respectively), there are clear outliers (e.g. one of two $4 \mathrm{MR}$ in $\mathrm{Pd}^{+2}$ is $0.5 \mathrm{eV}$ off the line).

Figure 9 demonstrates that there is a clear distinction in $\mathrm{NO}$ adsorption between $\mathrm{Pd}^{+} \mathrm{H}^{+}$ and $\mathrm{Pd}^{+2}$. For a similar $\Delta E_{\text {form }}, \mathrm{E}_{\mathrm{NO}}$ in $\mathrm{Pd}^{+} \mathrm{H}^{+}$is much stronger (by as much as $1 \mathrm{eV}$ ). For most of the $\mathrm{Al}$ pair arrangements, the $\mathrm{NO}$ binds more strongly to $\mathrm{Pd}^{+} \mathrm{H}^{+}$compared to $\mathrm{Pd}^{+2}$. We also find $\mathrm{NO}$ adsorption on $\mathrm{Pd}^{+} \mathrm{H}^{+}$to be stronger when the $\mathrm{Pd}^{+}$and $\mathrm{NO}$ unpaired electrons are paired (compared to two unpaired electrons) (Table S2). This might 
be one reason for the stronger binding on $\mathrm{Pd}^{+} \mathrm{H}^{+}$(given that $\mathrm{NO}$ adsorption on $\mathrm{Pd}^{+2}$ has an unpaired $\mathrm{NO}$ electron). Experimentally, it is unclear if $\mathrm{Pd}^{+} \mathrm{H}^{+}$is present under operating conditions; however, Figure 9 indicates that if present, it is a superior NO adsorption site compared to $\mathrm{Pd}^{+2}$.

Figure 9 also shows that $\mathrm{Al}$ pairs in the 6MR arrangement (especially in NNNN configuration), which has been discussed most extensively in the literature because they hold $\mathrm{Pd}^{+2}$ cations most stably, are weaker sites for $\mathrm{NO}$ adsorption compared to other $\mathrm{Al}$ arrangements. This is not unexpected since the more stable the $\mathrm{Pd}$, the more weakly it can bind to a guest molecule. It is striking, however, that the difference in $\Delta \mathrm{E}_{\mathrm{NO}}$ compared to the other $\mathrm{Al}$ arrangements (0.25-1.5 eV). Figure 9 also highlights how many of the CHA sites are very close in energy, especially for $\mathrm{Pd}^{+} \mathrm{H}^{+}$. Therefore, it is very difficult based on the small differences in energy values to discern spectroscopic data and assign them to specific sites. The results indicate that an ensemble of sites of very similar energies contribute similarly to the adsorption of NO. 


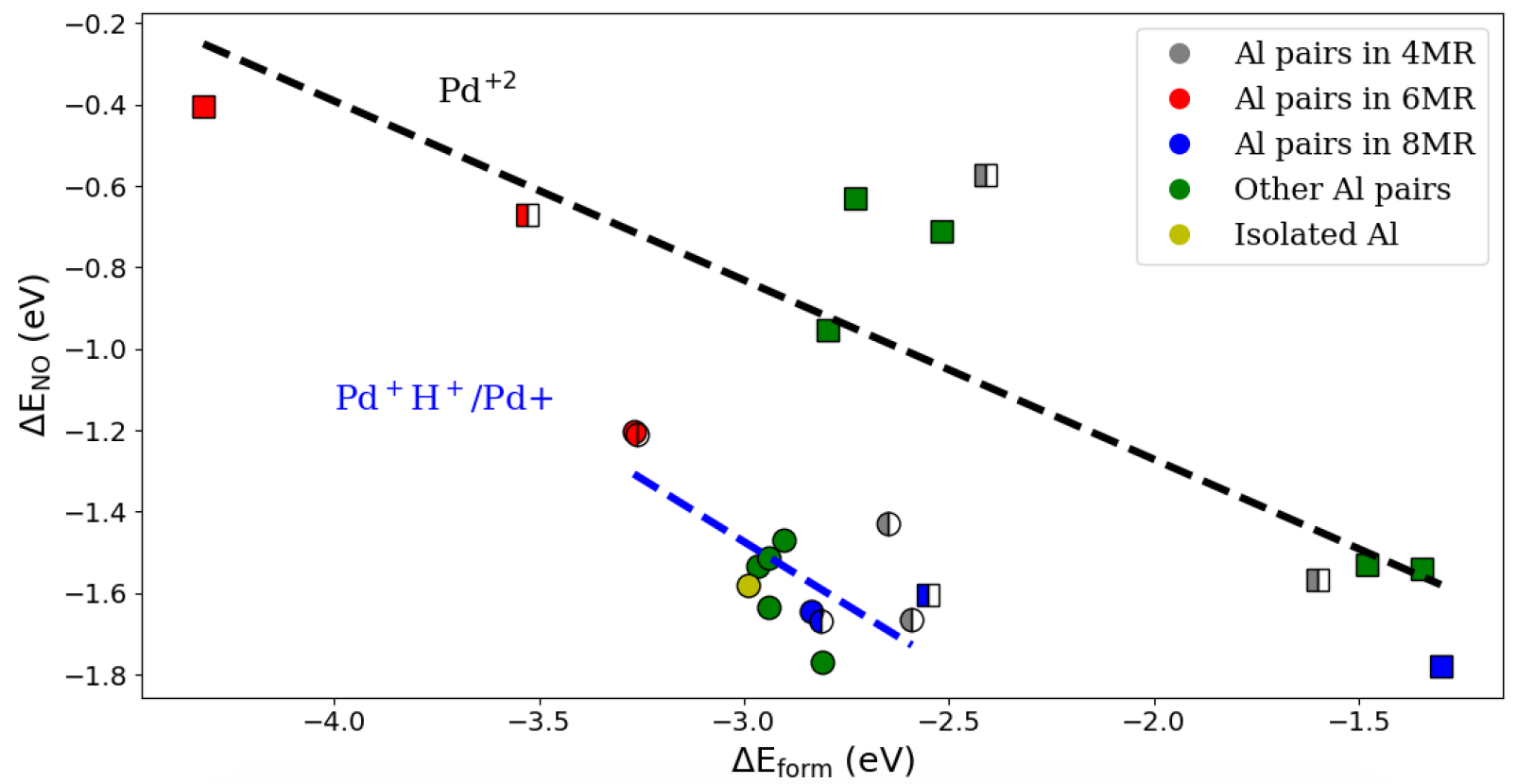

Figure 9: NO Binding energy versus Pd formation energy on CHA. The color coding refers to the type of $\mathrm{Al}$ in the $n$-MR. The marker shapes ( $\square$ and $\circ$ ) represent $\mathrm{Pd}^{+2}$ and $\mathrm{Pd}^{+} / \mathrm{Pd}^{+} \mathrm{H}^{+}$, respectively. The black and blue lines are based on fitting data for $\mathrm{Pd}^{+2}$ and $\mathrm{Pd}^{+} / \mathrm{Pd}^{+} \mathrm{H}^{+}$, respectively. Filled markers are used for $\mathrm{Al}$ pairs in NNNN configuration and half-filled markers are for isolated $\mathrm{Al}$ or $\mathrm{Al}$ in $\mathrm{NNN}$ configurations

\section{Conclusion}

We developed a high throughput screening approach for enumerating unique Al arrangements in zeolites, examined possible cation-exchanged sites, calculated energies via density functional theory (DFT) for stabilizing Pd cations in different locations, and determined favorable locations for the positioning of metal cations in a zeolite. Pd adsorption on CHA and BEA was used to illustrate the approach. After conducting thousands of individual calculations, we arrived at $\mathrm{Al}$ configurations that allow optimum Pd cation stability. Sites with $\mathrm{Al}$ in $6 \mathrm{MR}$ bind $\mathrm{Pd}$ cations most strongly, consistent with prior work [27, 28]. However, high throughput screening identifies other $\mathrm{Al}$ configurations, especially for $\mathrm{Pd}^{+} \mathrm{H}^{+}$, that bind Pd cations very stably. Many of these arrangements have not been considered previously for $\mathrm{CHA}$ and BEA. In addition, the most stable location for $\mathrm{Pd}$ is not always the most 
physically intuitive (e.g., inside a 5MR or 6MR). Lastly, we examined the impact of the high throughput approach on $\mathrm{NO}$ adsorption on Pd-exchanged-CHA. We generally find $\mathrm{Pd}^{+} \mathrm{H}^{+}$ to be more stable on $\mathrm{CHA}$ compared to $\mathrm{Pd}^{+2}$. Although $\mathrm{Al}$ pairs in $6 \mathrm{MR}$ are very stable sites for the $\mathrm{Pd}$ cation, $\mathrm{NO}$ adsorption on these sites is weaker compared to that for other $\mathrm{Al}$ configurations examined. This identifies sites that might play a critical role in the adsorption of NO in a PNA. Finally, we note that the DFT-based high throughput screening reported here provides a robust systematic path for identifying the most energetically favored cation exchange sites. While the method is applied here to zeolites, it could be extended to identify the energetically preferred location of cations in many other materials (e.g., MOFs).

\section{Methods}

\section{Theoretical calculations}

A hybrid quantum mechanics/molecular mechanics (QM/MM) approach was used to model the zeolite structure. Detailed implementation of this model can be found elsewhere [16]. The QM/MM approach has proven to account for long-range Coulombic and dispersive interactions, which are critical in describing the zeolite framework interactions with adsorbates [36]. Many studies have shown that the QM/MM approach gives a good prediction of experimental data for different zeolites and adsorbates [16, 32-34, 36, 42, 43]. This approach is also computationally more efficient than periodic calculations since it requires a smaller

number of QM atoms, especially when the unit cell contains a large number of atoms (e.g. BEA). All QM/MM calculations were done with a development version of Q-Chem [44].

The adsorbate(s) and a cluster encompassing the active site are described by QM and the rest of the zeolite is modeled by MM using a standard force field of the CHARMM type with the P2 parameter set [17]. During structural optimization, the QM region is allowed to relax while the MM region is fixed. The B97-D3 exchange functional [45], a generalized gradient approximation (GGA) exchange functional, is used as an initial filter 
to determine the optimum site of the cation followed by calculations done with the more accurate range-separated hybrid functional, $\omega$ B97X-D [46], which was shown to be among the best performing hybrid functionals in a benchmarking study [18]. An effective core potential was used on $\mathrm{Pd}$ atom. For each structure, the def2-SV(P) basis set was used to obtain the optimized structure geometry, and further energy refinement was done using a single-point calculation at the def2-TZVPD level of theory [47].

\section{Zeolite model}

The crystallographic structure of CHA and BEA were obtained from the International Zeolite Association (IZA) database [48]. Cluster models containing 696 and 810 tetrahedral atoms (T696 and T810) were used to model CHA and BEA topologies, respectively (Figure S15). The CHA cluster is based on the previous work from or group[27]. While earlier work has suggested that a 100 T-atom cluster model is sufficient [32], larger cluster models are used here due to the marginal additional computational cost and the extended active site region in some of the calculations. Each cluster was terminated with hydrogen atoms replacing terminal oxygen atoms.

\section{Data Availability}

The data that support the results within this paper and other findings of this study are available in the supporting information. 


\section{References}

1. Guisnet, M. \& Gilson, J.-P. Zeolites for cleaner technologies (Imperial College Press London, 2002).

2. Corma, A. From microporous to mesoporous molecular sieve materials and their use in catalysis. Chemical reviews 97, 2373-2420 (1997).

3. Kulprathipanja, S. Zeolites in industrial separation and catalysis (John Wiley \& Sons, 2010).

4. Paolucci, C. et al. Catalysis in a cage: Condition-dependent speciation and dynamics of exchanged cu cations in ssz-13 zeolites. Journal of the American Chemical Society 138, 6028-6048. ISSN: 15205126 (2016).

5. Janda, A., Vlaisavljevich, B., Lin, L.-C., Smit, B. \& Bell, A. T. Effects of zeolite structural confinement on adsorption thermodynamics and reaction kinetics for monomolecular cracking and dehydrogenation of n-butane. Journal of the American Chemical Society 138, 4739-4756 (2016).

6. Nørskov, J. K., Studt, F., Abild-Pedersen, F. \& Bligaard, T. Fundamental concepts in heterogeneous catalysis (John Wiley \& Sons, 2014).

7. Van Santen, R. A. Modern heterogeneous catalysis: an introduction (John Wiley \& Sons, 2017).

8. Olson, D. H., Khosrovani, N., Peters, A. W. \& Toby, B. H. Crystal structure of dehydrated CsZSM-5 (5.8 Al): evidence for nonrandom aluminum distribution. The Journal of Physical Chemistry B 104, 4844-4848 (2000).

9. Mentzen, B. \& Sacerdote-Peronnet, M. Prediction of preferred proton locations in HMFI/benzene complexes by molecular mechanics calculations. Comparison with NMR, structural and calorimetric results. Materials research bulletin 29, 1341-1348 (1994). 
10. SUN, X.-L., HUANG, C.-P., ZHANG, J. \& CHEN, B.-H. Location of Al and Acid Strength of Brynsted Acid in Beta Zeolite. Acta Physico-Chimica Sinica 25, 1136$1142(2009)$.

11. Mansoor, E., Head-Gordon, M. \& Bell, A. T. Computational modeling of the nature and role of Ga species for light alkane dehydrogenation catalyzed by Ga/H-MFI. ACS Catalysis 8, 6146-6162 (2018).

12. Ghorbanpour, A., Rimer, J. D. \& Grabow, L. C. Periodic, vdW-corrected density functional theory investigation of the effect of Al siting in H-ZSM-5 on chemisorption properties and site-specific acidity. Catalysis Communications 52, 98-102 (2014).

13. Jones, A. J. \& Iglesia, E. The Strength of Brønsted Acid Sites in Microporous Aluminosilicates. ACS Catalysis 5, 5741-5755. ISSN: 21555435 (2015).

14. Xing, B., Ma, J., Li, R. \& Jiao, H. Location, distribution and acidity of Al substitution in ZSM-5 with different $\mathrm{Si} / \mathrm{Al}$ ratios-a periodic DFT computation. Catalysis Science $\&$ Technology 7, 5694-5708 (2017).

15. Zhang, N., Liu, C., Ma, J., Li, R. \& Jiao, H. Determining the structures, acidity and adsorption properties of Al substituted HZSM-5. Physical Chemistry Chemical Physics 21, 18758-18768 (2019).

16. Zimmerman, P. M., Head-Gordon, M. \& Bell, A. T. Selection and validation of charge and Lennard-Jones parameters for QM/MM simulations of hydrocarbon interactions with zeolites. Journal of chemical theory and computation 7, 1695-1703 (2011).

17. Li, Y.-P., Gomes, J., Mallikarjun Sharada, S., Bell, A. T. \& Head-Gordon, M. Improved force-field parameters for QM/MM simulations of the energies of adsorption for molecules in zeolites and a free rotor correction to the rigid rotor harmonic oscillator model for adsorption enthalpies. The Journal of Physical Chemistry C 119, 1840-1850 (2015). 
18. Mardirossian, N. \& Head-Gordon, M. Thirty years of density functional theory in computational chemistry: an overview and extensive assessment of 200 density functionals. Molecular Physics 115, 2315-2372 (2017).

19. Kim, J., Abouelnasr, M., Lin, L.-C. \& Smit, B. Large-scale screening of zeolite structures for CO2 membrane separations. Journal of the American Chemical Society 135, 75457552 (2013).

20. Lee, Y. et al. High-throughput screening approach for nanoporous materials genome using topological data analysis: application to zeolites. Journal of chemical theory and computation 14, 4427-4437 (2018).

21. Kim, J. et al. Large-scale computational screening of zeolites for ethane/ethene separation. Langmuir 28, 11914-11919 (2012).

22. Sławek, A., Grzybowska, K., Vicent-Luna, J. M., Makowski, W. \& Calero, S. Adsorption of Cyclohexane in Pure Silica Zeolites: High-Throughput Computational Screening Validated by Experimental Data. ChemPhysChem 19, 3364-3371 (2018).

23. Siepmann, J. I., Bai, P., Tsapatsis, M., Knight, C. \& Deem, M. W. Discovery of optimal zeolites for challenging separations and chemical conversions through predictive materials modeling. APS 2015, B16-003 (2015).

24. Chen, H.-Y. et al. Low temperature NO storage of zeolite supported Pd for low temperature diesel engine emission control. Catalysis Letters 146, 1706-1711 (2016).

25. Gu, Y. \& Epling, W. S. Passive NOx adsorber: An overview of catalyst performance and reaction chemistry. Applied Catalysis A: General 570, 1-14 (2019).

26. Ji, Y., Bai, S. \& Crocker, M. Al2O3-based passive NOx adsorbers for low temperature applications. Applied Catalysis B: Environmental 170, 283-292 (2015).

27. Van der Mynsbrugge, J., Head-Gordon, M. \& Bell, A. T. Computational modeling predicts the stability of both $\mathrm{Pd}+$ and $\mathrm{Pd} 2+$ ion-exchanged into H-CHA. Journal of Materials Chemistry A 9, 2161-2174 (2021). 
28. Mandal, K. et al. Condition-Dependent Pd Speciation and NO Adsorption in Pd/Zeolites. ACS Catalysis 10, 12801-12818 (2020).

29. Loewenstein, W. The distribution of aluminum in the tetrahedra of silicates and aluminates. American Mineralogist: Journal of Earth and Planetary Materials 39, 92-96 (1954).

30. Verstraelen, T., Van Speybroeck, V. \& Waroquier, M. ZEOBUILDER: A GUI Toolkit for the Construction of Complex Molecular Structures on the Nanoscale with Building Blocks. Journal of Chemical Information and Modeling 48, 1530-1541. ISSN: 1549-9596. http://pubs.acs.org/doi/abs/10.1021/ci8000748 (2008).

31. Larsen, A. H. et al. The atomic simulation environment-a Python library for working with atoms. Journal of Physics: Condensed Matter 29, 273002. http://stacks.iop. org/0953-8984/29/i=27/a=273002 (2017).

32. Gomes, J., Zimmerman, P. M., Head-Gordon, M. \& Bell, A. T. Accurate prediction of hydrocarbon interactions with zeolites utilizing improved exchange-correlation functionals and QM/MM methods: benchmark calculations of adsorption enthalpies and application to ethene methylation by methanol. The Journal of Physical Chemistry C 116, 15406-15414 (2012).

33. Mallikarjun Sharada, S., Zimmerman, P. M., Bell, A. T. \& Head-Gordon, M. Insights into the kinetics of cracking and dehydrogenation reactions of light alkanes in H-MFI. The Journal of Physical Chemistry C 117, 12600-12611 (2013).

34. Li, Y.-P., Head-Gordon, M. \& Bell, A. T. Theoretical study of 4-(hydroxymethyl) benzoic acid synthesis from ethylene and 5-(hydroxymethyl) furoic acid catalyzed by SnBEA. ACS Catalysis 6, 5052-5061 (2016).

35. Dinda, S., Govindasamy, A., Genest, A. \& Rösch, N. Modeling Catalytic Steps on Extra-Framework Metal Centers in Zeolites. A Case Study on Ethylene Dimerization. The Journal of Physical Chemistry C 118, 25077-25088 (2014). 
36. Mansoor, E., Van der Mynsbrugge, J., Head-Gordon, M. \& Bell, A. T. Impact of longrange electrostatic and dispersive interactions on theoretical predictions of adsorption and catalysis in zeolites. Catalysis Today 312, 51-65 (2018).

37. Sastre, G., Fornes, V. \& Corma, A. On the preferential location of Al and proton siting in zeolites: a computational and infrared study. The Journal of Physical Chemistry B 106, 701-708 (2002).

38. Dědeček, J. \& Wichterlová, B. Co2+ Ion Siting in Pentasil-Containing Zeolites. I. Co2+ Ion Sites and Their Occupation in Mordenite. A Vis- NIR Diffuse Reflectance Spectroscopy Study. The Journal of Physical Chemistry B 103, 1462-1476 (1999).

39. Dědeček, J., Sobalık, Z. \& Wichterlová, B. Siting and distribution of framework aluminium atoms in silicon-rich zeolites and impact on catalysis. Catalysis Reviews $\mathbf{5 4}$, $135-223(2012)$.

40. Khivantsev, K. et al. Stabilization of super electrophilic Pd+ 2 cations in small-pore SSZ-13 zeolite. The Journal of Physical Chemistry C 124, 309-321 (2019).

41. Abild-Pedersen, F. et al. Scaling properties of adsorption energies for hydrogen-containing molecules on transition-metal surfaces. Physical review letters 99, 016105 (2007).

42. Li, Y.-P., Head-Gordon, M. \& Bell, A. T. Computational study of p-xylene synthesis from ethylene and 2, 5-dimethylfuran catalyzed by H-BEA. The Journal of Physical Chemistry C 118, 22090-22095 (2014).

43. Li, Y.-P., Head-Gordon, M. \& Bell, A. T. Analysis of the reaction mechanism and catalytic activity of metal-substituted beta zeolite for the isomerization of glucose to fructose. Acs Catalysis 4, 1537-1545 (2014).

44. Shao, Y. et al. Advances in molecular quantum chemistry contained in the Q-Chem 4 program package. Molecular Physics 113, 184-215 (2015).

45. Grimme, S. Semiempirical GGA-type density functional constructed with a long-range dispersion correction. Journal of computational chemistry 27, 1787-1799 (2006). 
46. Chai, J.-D. \& Head-Gordon, M. Long-range corrected hybrid density functionals with damped atom-atom dispersion corrections. Physical Chemistry Chemical Physics 10, 6615-6620 (2008).

47. Weigend, F. \& Ahlrichs, R. Balanced basis sets of split valence, triple zeta valence and quadruple zeta valence quality for $\mathrm{H}$ to Rn: Design and assessment of accuracy. Physical Chemistry Chemical Physics 7, 3297-3305 (2005).

48. Meier, W. M., Olson, D. H. \& Baerlocher, C. Atlas of the zeolite structure types. Zeolites 17 (1996). 


\section{Acknowledgement}

This material is based upon work supported by the U.S. Department of Energy's Office of Energy Efficiency and Renewable Energy (EERE) under the Vehicle Technologies Program Award Number DE-EE0008213. This research used resources of the National Energy Research Scientific Computing Center, a DOE Office of Science User Facility supported by the Office of Science of the U.S. Department of Energy under Contract No. DE-AC0205CH11231. The authors also thank UC Berkeley's Molecular Graphics and Computation Facility (supported by NIH S10OD023532) for their computational resources. H.A. would like Saudi Aramco for their funding, and MHG acknowledges funding from the National Institutes of Health under Grant No. 5U01GM121667. This work used the Extreme Science and Engineering Discovery Environment (XSEDE) Comet at the service-provider through allocation TG-CE200085.

\section{Author Contributions}

H.A and A.T.B conceptualized the project. H.A, M.H.G and A.T.B developed the methodology. H.A. wrote the code, performed the calculations, and wrote the original draft. All authors participated in data analysis and editing the manuscript. M.H.G and A.T.B supervised the research reported in the paper. 


\title{
Supporting Information Available
}

Assessing the stability of Pd-exchanged sites in zeolites with the aid of a high throughput workflow

\author{
Supporting Information
}

\author{
Hassan Aljama ${ }^{\dagger}$, Martin Head-Gordon ${ }^{\ddagger}$ and Alexis T. Bell ${ }^{*, \dagger}$ \\ ${ }^{\dagger}$ Department of Chemical and Biomolecular Engineering, University of \\ California, Berkeley, California \\ ${ }^{\ddagger}$ Department of Chemistry, University of California, Berkeley, California
}


All energies and xyz coordinates of the optimized geometries are available in the electronic supporting information (ESI). The nomenclature used to tabulate the data is as follow: zeolite name (CHA or BEA) - a number representing structure with a unique $\mathrm{Al}$ arrangement - adsorbate name $\left(\mathrm{Pd}^{+2}, \mathrm{Pd}^{+} \mathrm{H}^{+}, \mathrm{Pd}^{+}, \mathrm{H}^{+}\right.$or $\left.\mathrm{H}^{+} \mathrm{H}^{+}\right)$- a number representing an initial position of the adsorbate - level of theory (GGA or hGGA) - type of calculations (opt for optimization and sp for single point calculation). 
a.

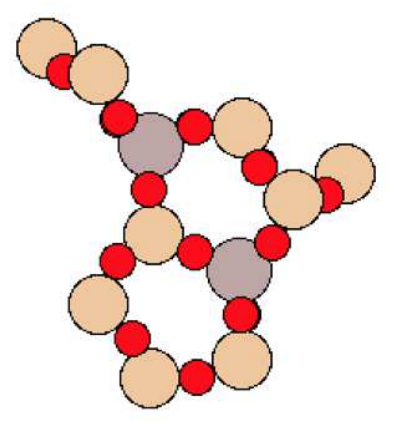

BEA-2

c.

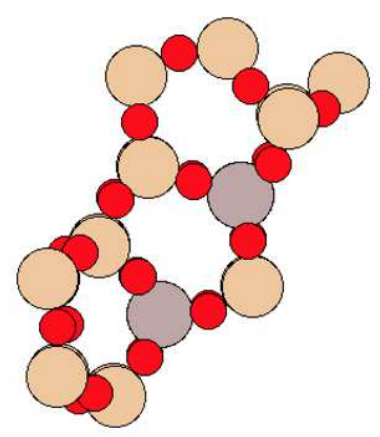

b.

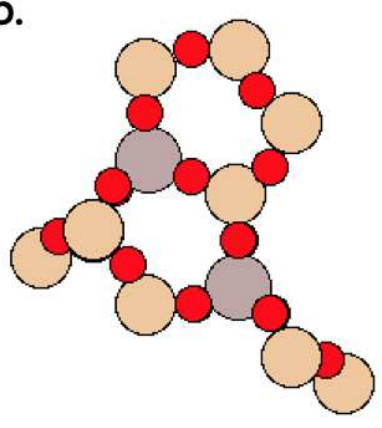

BEA-I I

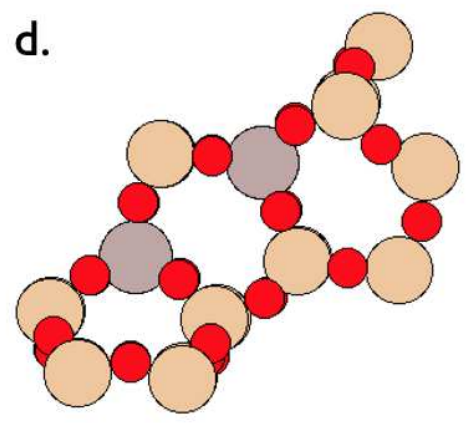

Figure S1: Images of the QM atoms in four BEA structures. BEA-2 structure is shown in a. alongside a similar structure in b. BEA-11 is shown in c. alongside a similar structure in d. The structures similar to BEA-2 and BEA-11 (b. and d., respectively) are not exactly identical, as calculated by the nuclear repulsion energy, but share the same connectivity to surrounding $\mathrm{Si}$ and $\mathrm{O}$ atoms (types of MR). The same color coding as in Figure 5. 
a.

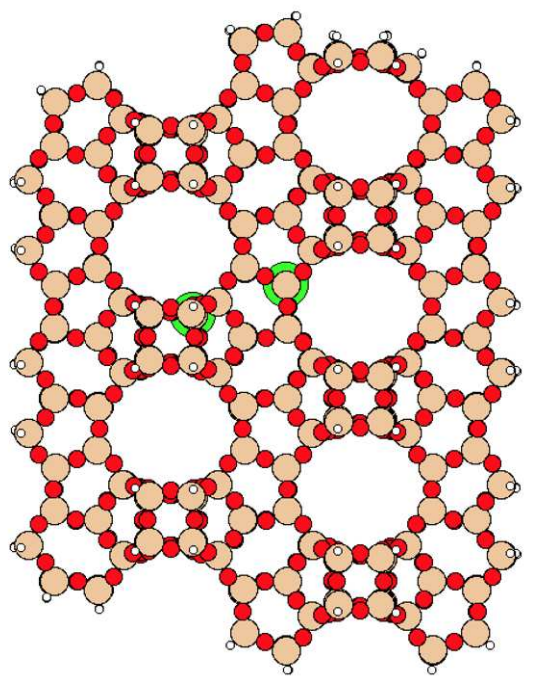

b.

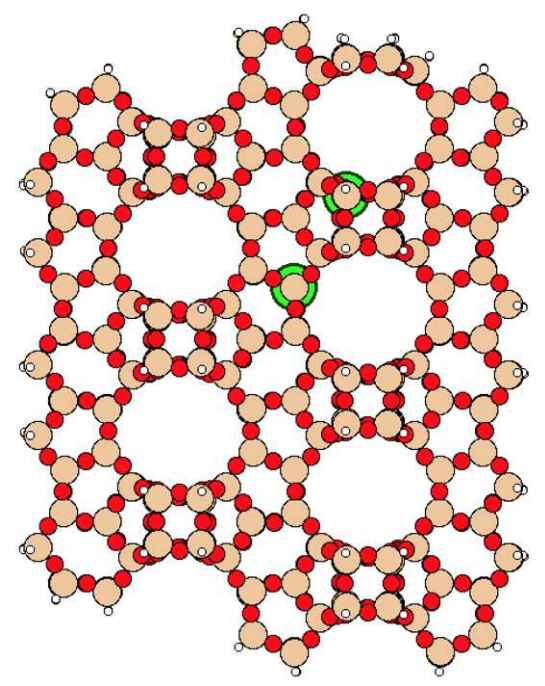

Figure S2: Example of two BEA clusters (a. and b.) where $\mathrm{Al}$ atoms are not in the same MR and are on opposite sides of the open cage. The same color coding as in Figure 5, however, for clarity purposes, $\mathrm{Al}$ atoms are enlarged and are shown in green 


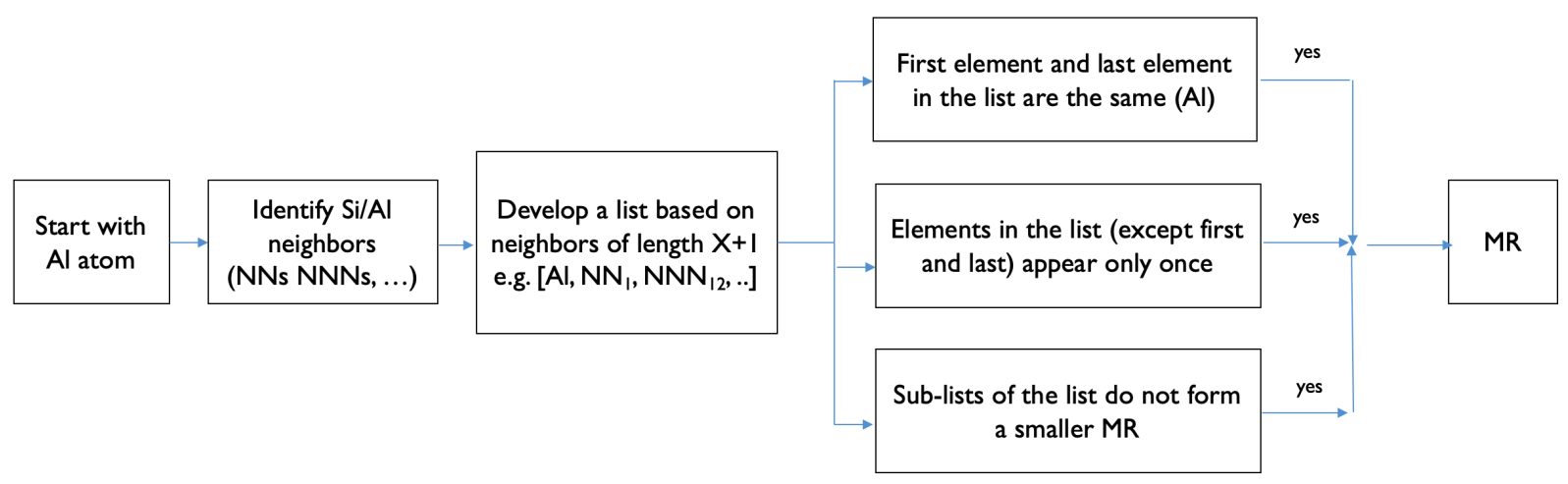

Figure S3: Flow diagram for determining if $\mathrm{Al}$ atom is in an $\mathrm{X} \mathrm{MR}$ (where $\mathrm{X}$ refers to the length of the MR). First, starting with an Al atom, Si/Al neighbors (NN, NNN, NNNN) are identified similar to the procedure described in Figure 2. This is done up to the $\mathrm{X}+1$ neighbor. Based on the neighbors, lists are developed (an example of a list is $\left[\mathrm{Al}, \mathrm{NN}_{1}\right.$, $\left.\mathrm{NNN}_{11}, ..\right]$, where $\mathrm{NN}_{1}$ refers to the first $\mathrm{NN}$ of the starting $\mathrm{Al}$ and $\mathrm{NNN}_{11}$ is the first $\mathrm{NN}$ to $\mathrm{NN}_{1}$ ). For each list, the following checks are made: first and last element of the list are the same (the starting $\mathrm{Al}$ atom), no element in the list (with the exception of the starting $\mathrm{Al}$ atom) appears twice in the list, and no sub-list of the list form a MR smaller than X. If a list passes those checks, then $\mathrm{Al}$ is part of XMR. 


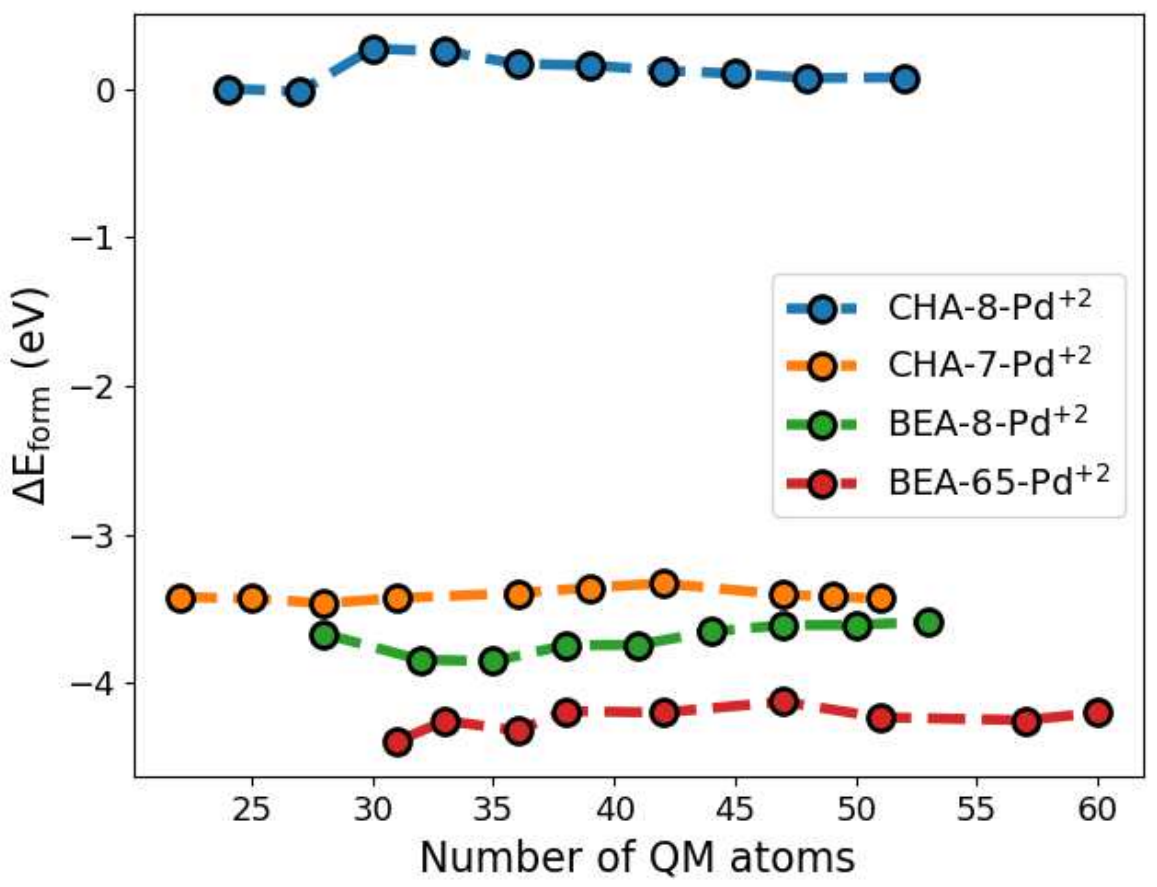

Figure S4: Impact of the number of atoms selected in the QM region on the convergence of the QM/MM calculations ( $\Delta E_{\text {form }}$ is defined in equation 2). Calculations were done using $\omega \mathrm{B} 97 \mathrm{X}-\mathrm{D}$ functional. 
a.

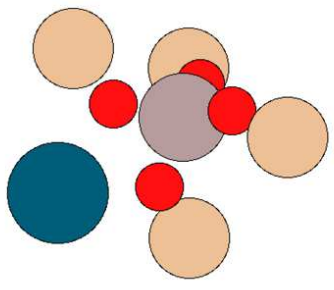

b.

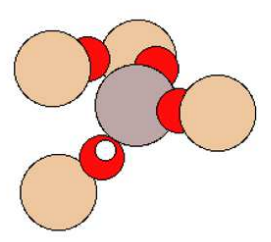

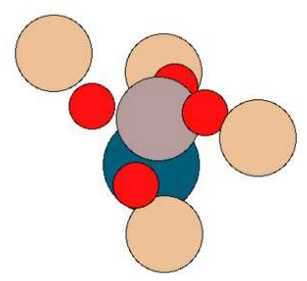
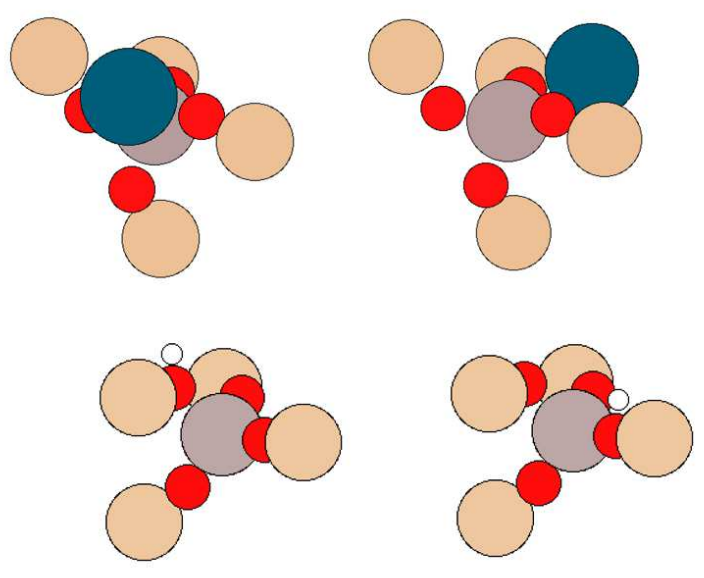

Figure S5: Example of a. Pd cation and b. proton placement near the four oxygens neighboring $\mathrm{Al}$ atom. For clarity, only $\mathrm{Si}$ in $\mathrm{NN}$ position and $\mathrm{O}$ neighboring $\mathrm{Al}$ are shown. The position of cation/proton is determined by finding the middle distance between neighboring oxygen, and then adding a displacement from the $\mathrm{Al}$ atom (usually 1-1.5 A). The same color coding as in Figure 5. 
Table S1: Comparison of the stability order (from most stable to 5th most stable) on 3 different structures (BEA-9, BEA-52 and BEA-6) at two levels of theory (GGA and hGGA). The adsorbate is $\mathrm{Pd}^{+} \mathrm{H}^{+}$. For simplicity, only the 5 most stable structures are shown out of the 32. The two results do not always yield the same order, however, the most stable structure at the hGGA level always appears among the 5 most stable structures at the GGA level. This means following the approach in Figure 1 yields the same results as doing all the calculations using $\omega$ B97X-D.

\begin{tabular}{|c|c|c|c|c|}
\hline Stability & Theory Level & BEA-9 & BEA-52 & BEA-63 \\
\hline \multirow[t]{2}{*}{$1 \mathrm{st}$} & GGA & BEA-9-Pd ${ }^{+} \mathrm{H}^{+}-3$ & BEA-52-Pd ${ }^{+} \mathrm{H}^{+}-24$ & BEA-63-Pd ${ }^{+} \mathrm{H}^{+}-26$ \\
\hline & hGGA & BEA-9-Pd ${ }^{+} \mathrm{H}^{+}-12$ & BEA-52-Pd ${ }^{+} \mathrm{H}^{+}-24$ & BEA-63-Pd ${ }^{+} \mathrm{H}^{+}-25$ \\
\hline \multirow[t]{2}{*}{ 2nd } & GGA & BEA-9-Pd ${ }^{+} \mathrm{H}^{+}-11$ & BEA-52-Pd ${ }^{+} \mathrm{H}^{+}-4$ & BEA-63-Pd ${ }^{+} \mathrm{H}^{+}-25$ \\
\hline & hGGA & BEA-9-Pd ${ }^{+} \mathrm{H}^{+}-11$ & BEA-52-Pd ${ }^{+} \mathrm{H}^{+}-23$ & BEA-63-Pd ${ }^{+} \mathrm{H}^{+}-26$ \\
\hline \multirow[t]{2}{*}{$3 \mathrm{rd}$} & GGA & BEA-9-Pd ${ }^{+} \mathrm{H}^{+}-12$ & BEA-52-Pd ${ }^{+} \mathrm{H}^{+}-3$ & BEA-63-Pd ${ }^{+} \mathrm{H}^{+}-5$ \\
\hline & hGGA & BEA-9-Pd ${ }^{+} \mathrm{H}^{+}-3$ & BEA-52-Pd ${ }^{+} \mathrm{H}^{+}-1$ & BEA-63-Pd ${ }^{+} \mathrm{H}^{+}-5$ \\
\hline \multirow[t]{2}{*}{ 4th } & GGA & BEA-9-Pd ${ }^{+} \mathrm{H}^{+}-24$ & BEA-52-Pd ${ }^{+} \mathrm{H}^{+}-27$ & BEA-63-Pd ${ }^{+} \mathrm{H}^{+}-24$ \\
\hline & hGGA & BEA-9-Pd ${ }^{+} \mathrm{H}^{+}-24$ & BEA-52-Pd ${ }^{+} \mathrm{H}^{+}-27$ & BEA-63-Pd ${ }^{+} \mathrm{H}^{+}-24$ \\
\hline \multirow[t]{2}{*}{5 th } & GGA & BEA-9-Pd ${ }^{+} \mathrm{H}^{+}-27$ & BEA-52-Pd ${ }^{+} \mathrm{H}^{+}-1$ & BEA-63-Pd ${ }^{+} \mathrm{H}^{+}-16$ \\
\hline & hGGA & BEA-9-Pd ${ }^{+} \mathrm{H}^{+}-27$ & BEA-52-Pd ${ }^{+} \mathrm{H}^{+}-4$ & BEA-63-Pd ${ }^{+} \mathrm{H}^{+}-16$ \\
\hline
\end{tabular}




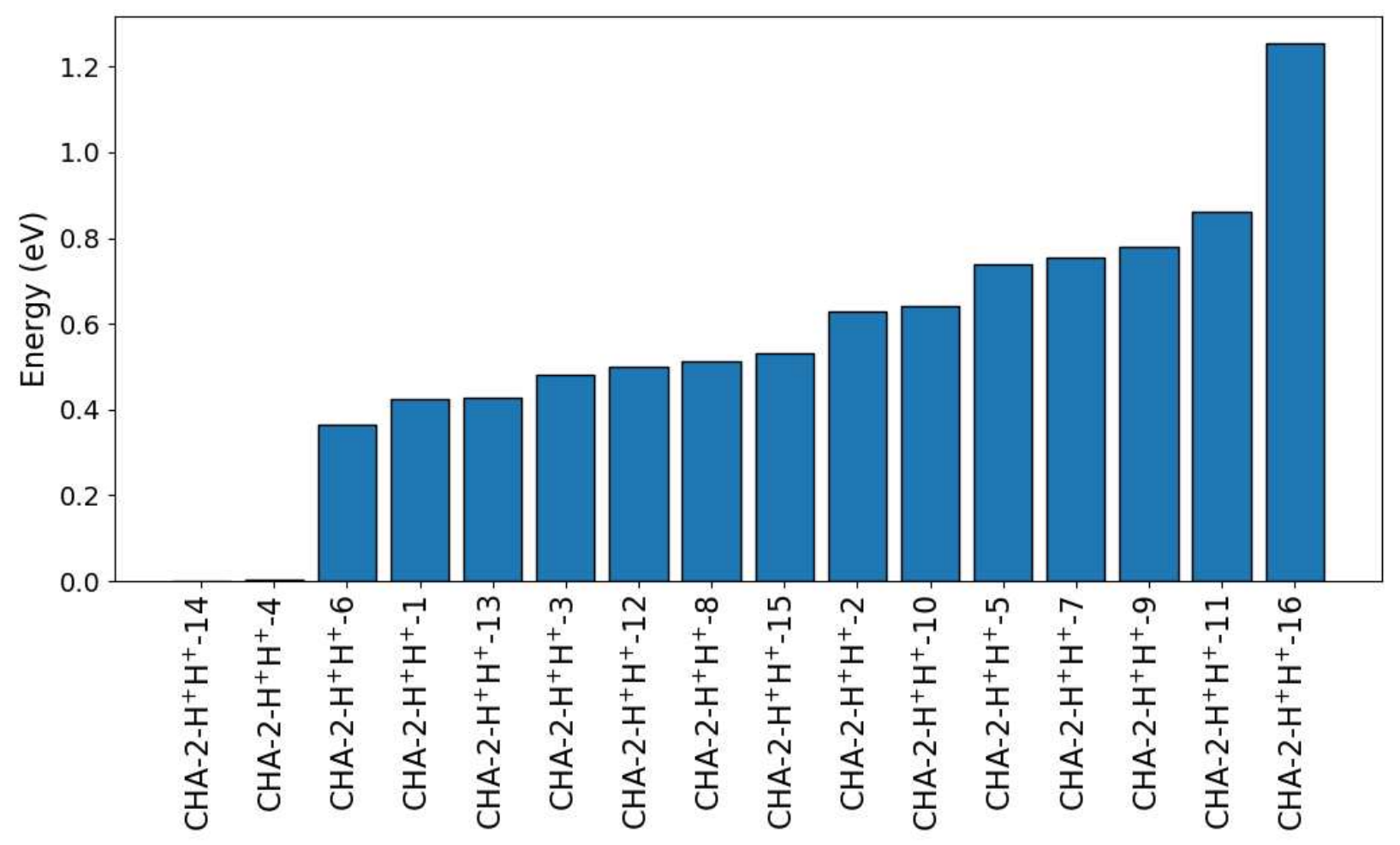

Figure S6: CHA-2 optimum proton locations search results. Each data represents the optimum energy based on a different initial position of the protons. The $\mathrm{x}$-axis refers to the index of the structure in the database in the SI and the y-axis is the energy relative to the most stable structure (CHA-2- $\left.\mathrm{H}^{+} \mathrm{H}^{+}-14\right)$. Calculations were done using the $\omega \mathrm{B} 97 \mathrm{X}-\mathrm{D}$ functional. 


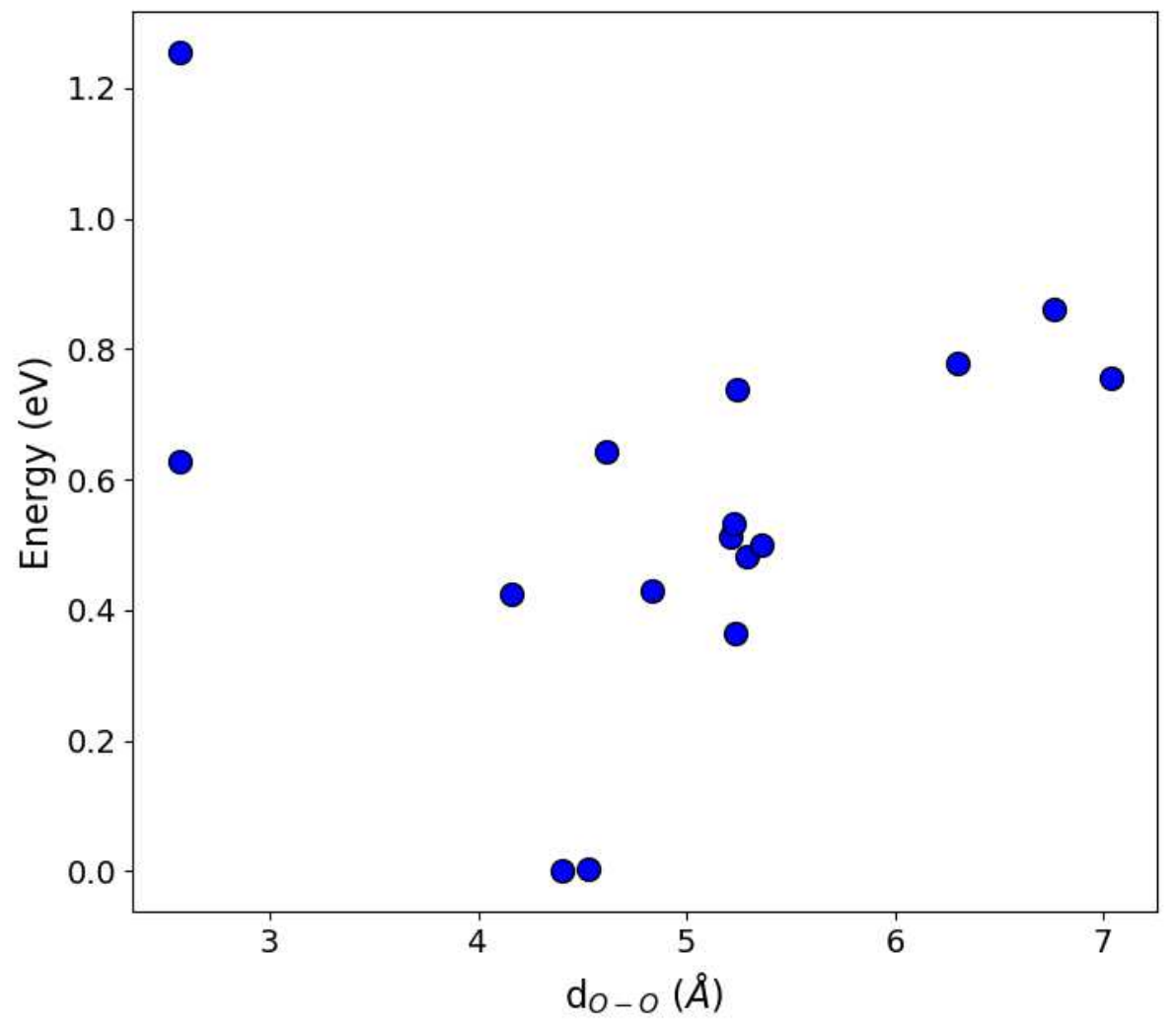

Figure S7: CHA-2 optimum proton locations search results. Each data represents a different initial position of the proton. The $\mathrm{x}$-axis refers to the $\mathrm{O}-\mathrm{O}$ distance (where the oxygen is the atom $\mathrm{H}$ adsorbs on) in the optimized structure and the y-axis is the energy relative to the most stable structure (CHA-2- $\left.\mathrm{H}^{+} \mathrm{H}^{+}-14\right)$ 


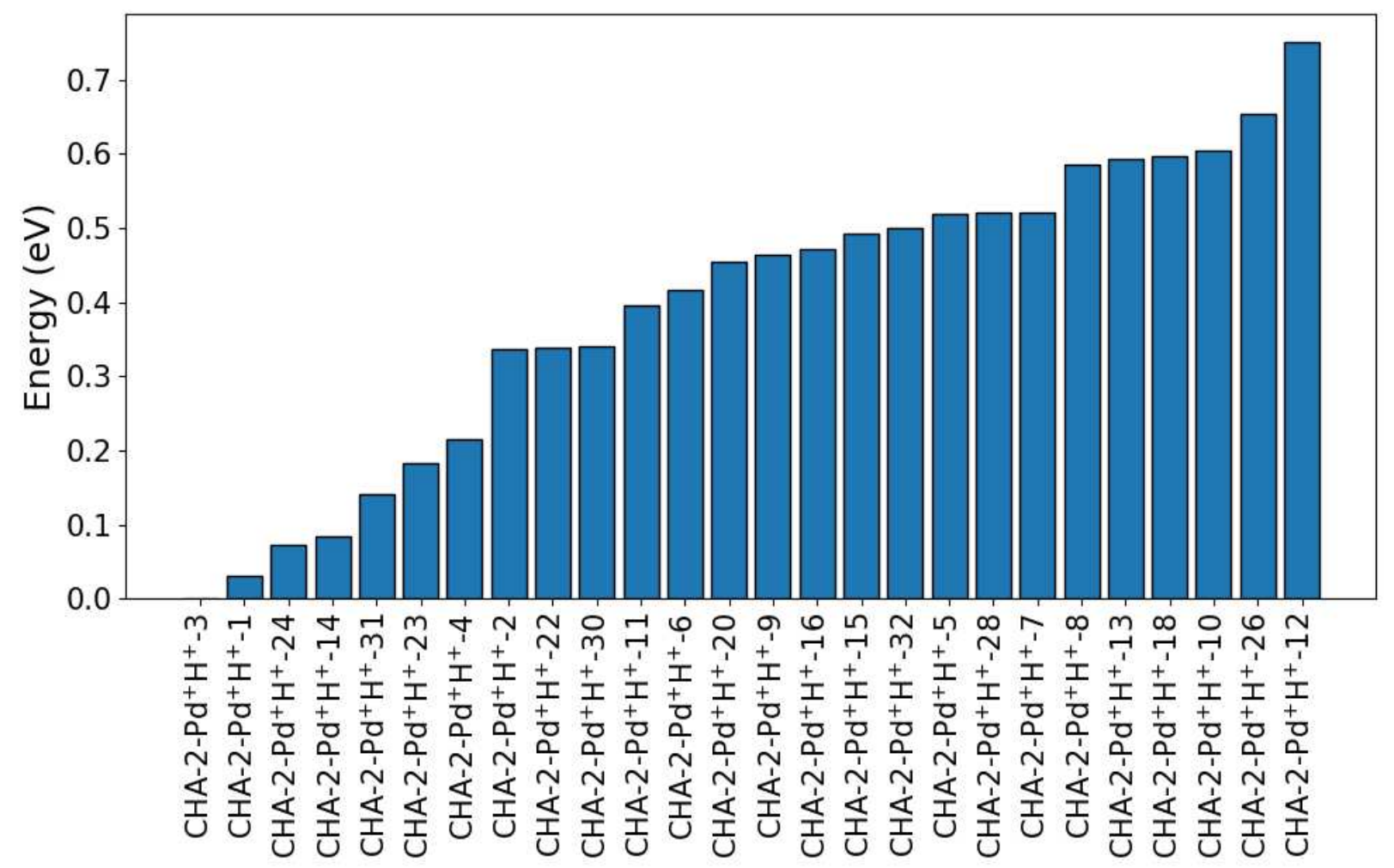

Figure S8: CHA-2 optimum $\mathrm{Pd}^{+} \mathrm{H}^{+}$locations search results. Each data represents a different initial position of $\mathrm{Pd}^{+} \mathrm{H}^{+}$. The $\mathrm{x}$-axis refers to the index of the structure in the database and the $y$-axis is the energy relative to the most stable structure $\left(\mathrm{CHA}-2-\mathrm{Pd}^{+} \mathrm{H}^{+}-3\right)$. Calculations were done using the $\omega \mathrm{B} 97 \mathrm{X}-\mathrm{D}$ functional. 
a.

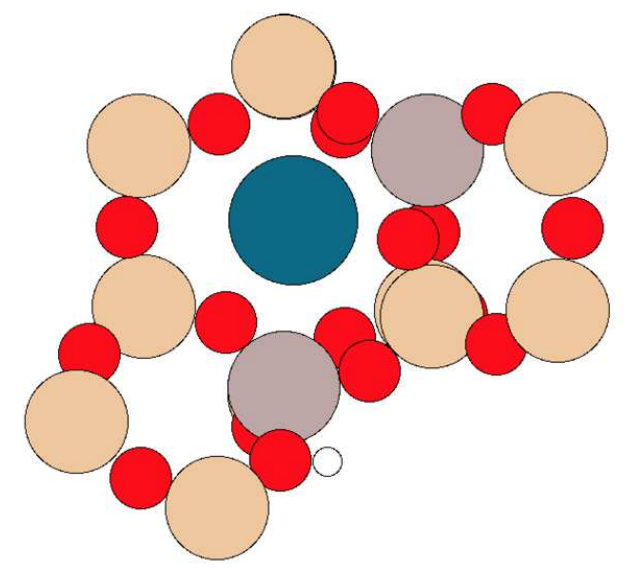

b.

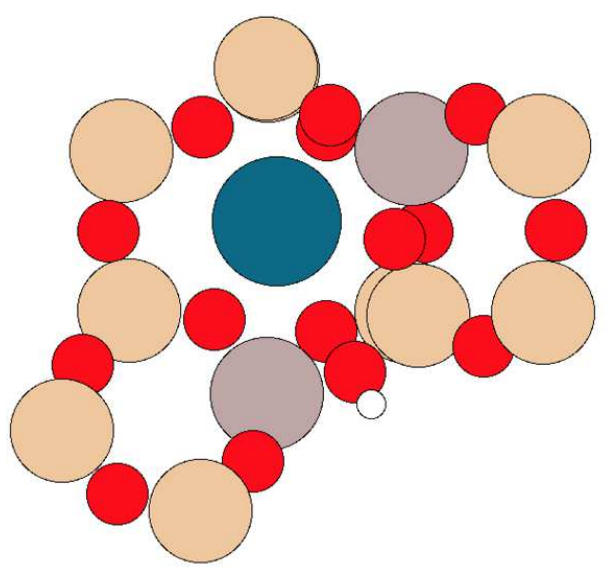

Figure S9: QM images of the optimized geometry of a. CHA-3-Pd $\mathrm{P}^{+}-21$ and b. CHA$3-\mathrm{Pd}^{+} \mathrm{H}^{+}-17$. Despite only a change in the proton position, there is $>0.4 \mathrm{eV}$ in energy difference between the two optimized geometries. The same color coding as in Figure 5 
a.

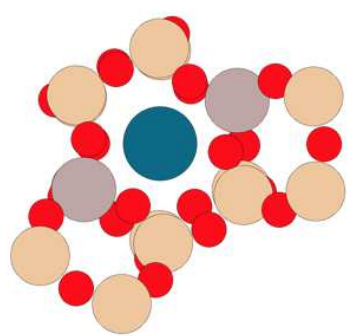

e.

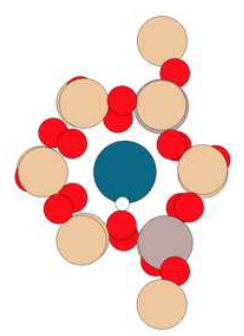

b.

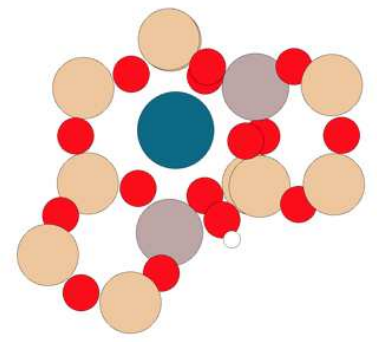

f.

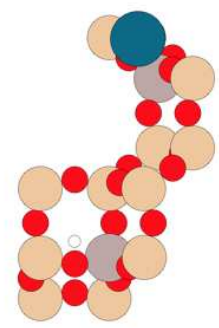

c.

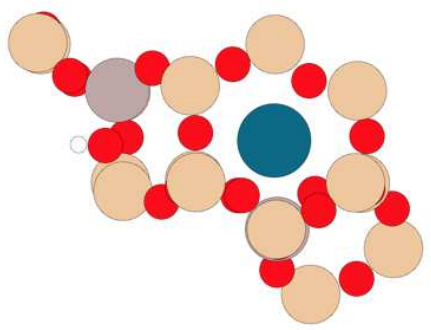

g.

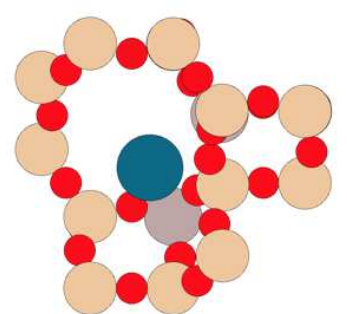

d.

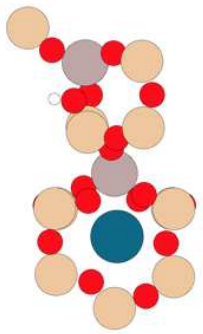

h.

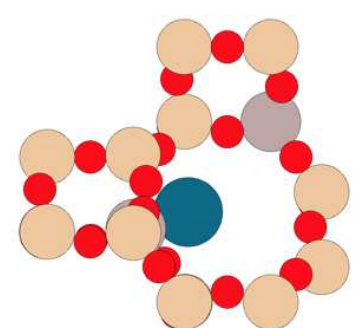

Figure S10: QM region images of the optimized geometry of a. $\mathrm{Pd}^{+} \mathrm{H}^{+}$on $\mathrm{CHA}-7 \mathrm{~b} . \mathrm{Pd}^{+} \mathrm{H}^{+}$ on CHA-3 c. $\mathrm{Pd}^{+} \mathrm{H}^{+}$on $\mathrm{CHA}-8 \mathrm{~d}$. $\mathrm{Pd}^{+} \mathrm{H}^{+}$on $\mathrm{CHA}-6$ e. $\mathrm{Pd}^{+} \mathrm{H}^{+}$on $\mathrm{CHA}-9 \mathrm{f} . \mathrm{Pd}^{+} \mathrm{H}^{+}$on CHA-12 g. $\mathrm{Pd}^{+2}$ on CHA-5 and h. $\mathrm{Pd}^{+2}$ on CHA-10. The same color coding as in Figure 5. 


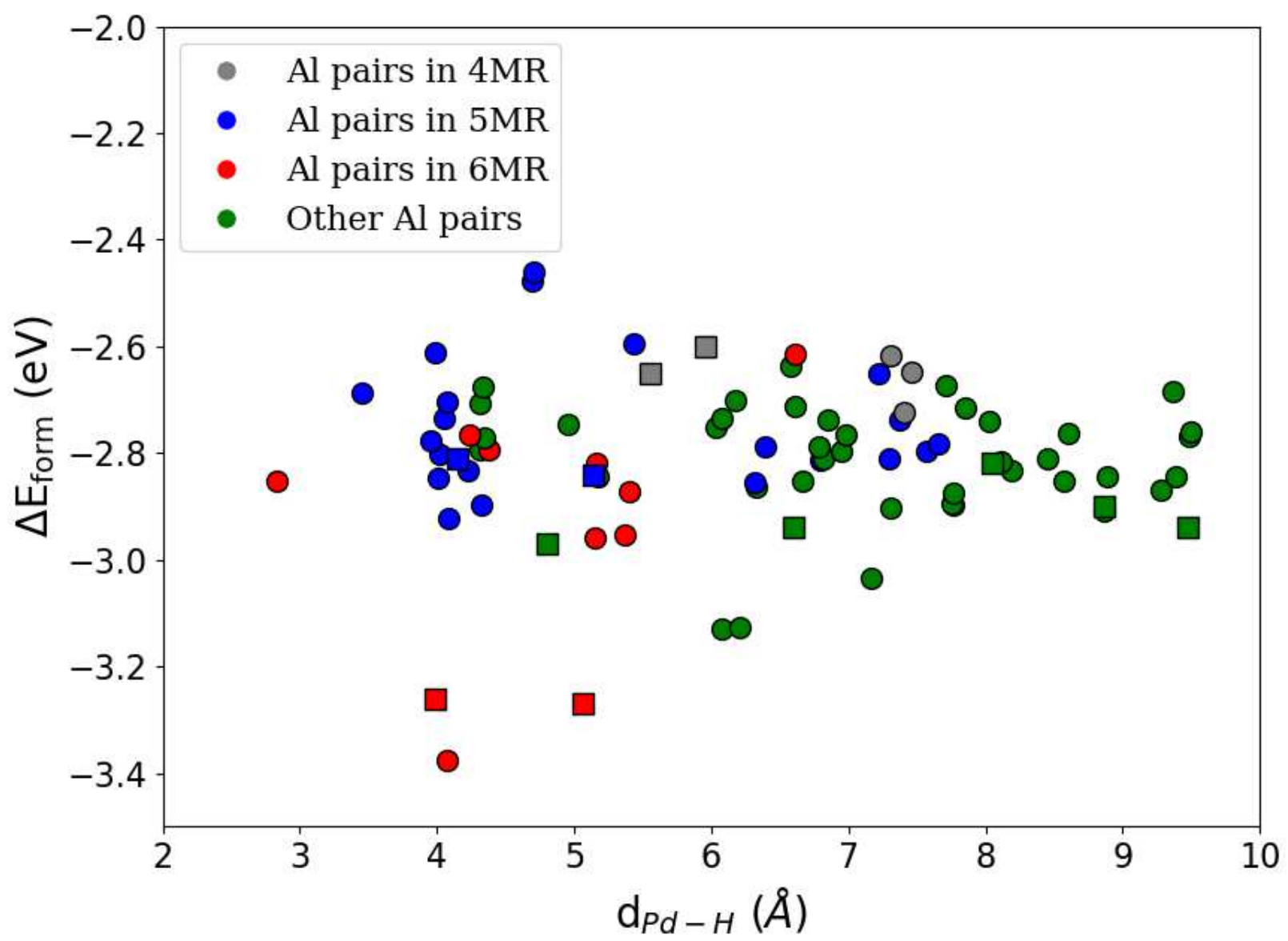

Figure S11: $\Delta \mathrm{E}_{\text {form }}$ as a function of the distance between $\mathrm{Pd}$ and $\mathrm{H}$ in $\mathrm{Pd}^{+} \mathrm{H}^{+}$optimized geometry on CHA ( $\square$ ) and BEA (o) 

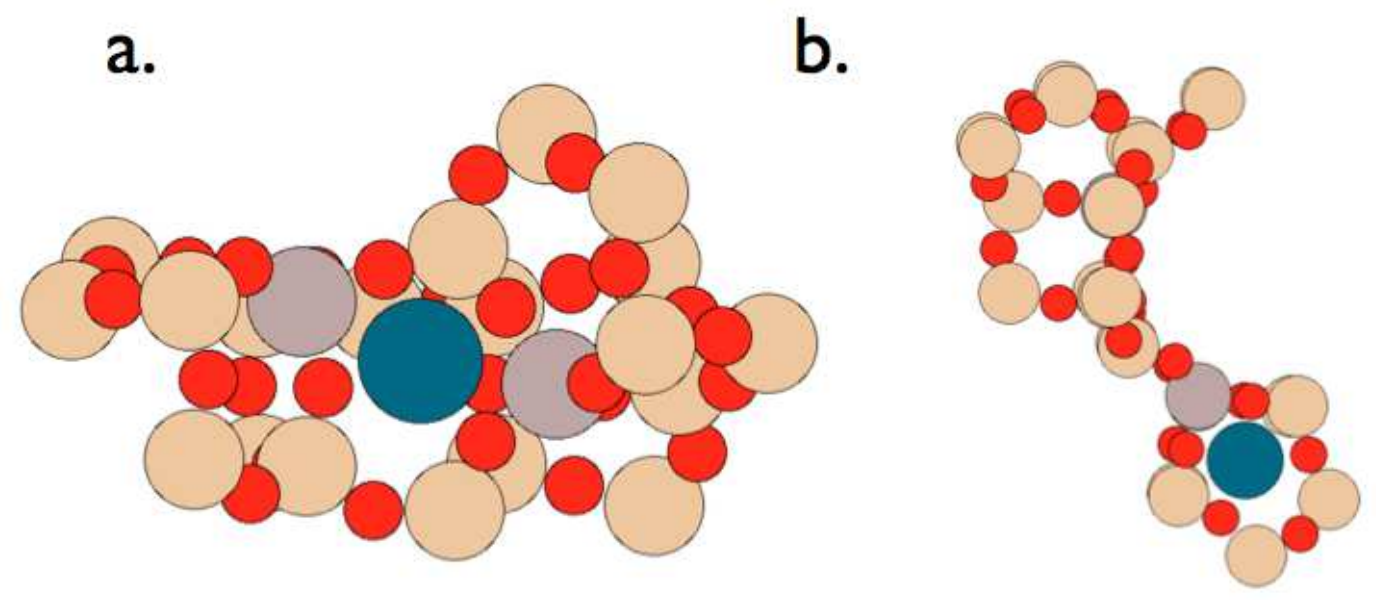

c.
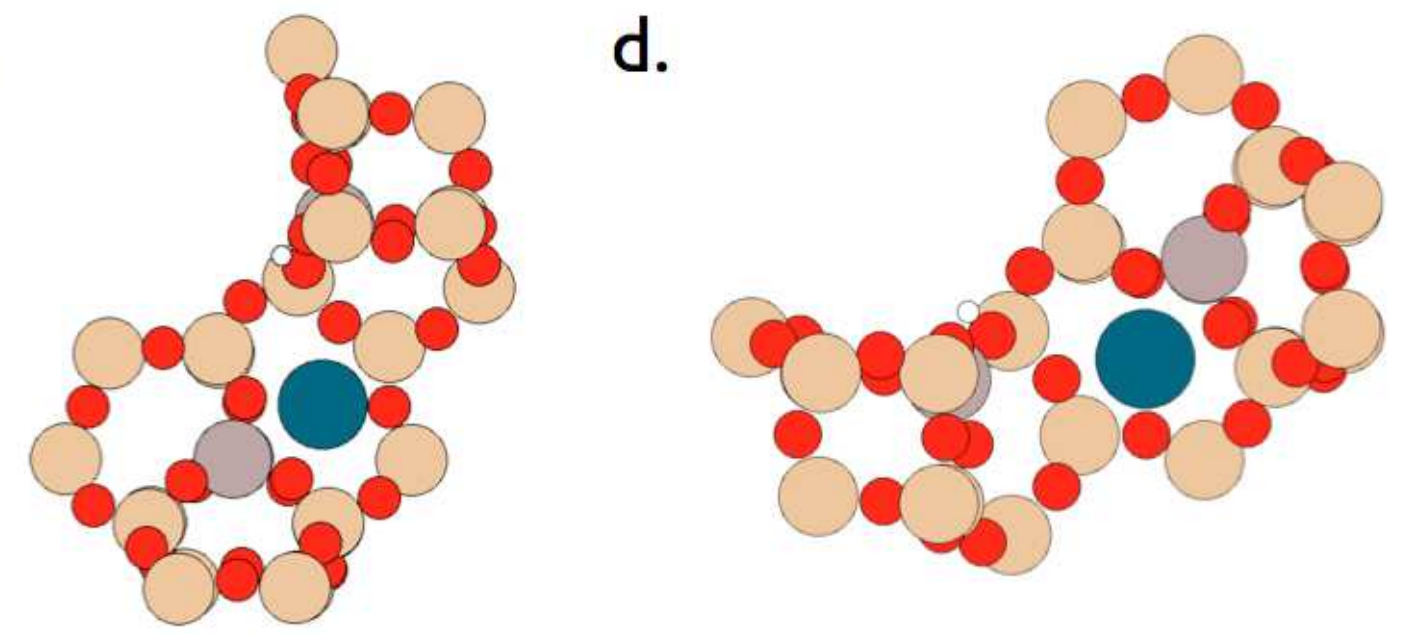

Figure S12: QM region images of optimized geometry of a. $\mathrm{Pd}^{+2}$ on BEA-8 b. $\mathrm{Pd}^{+2}$ on BEA-55 c. $\mathrm{Pd}^{+} \mathrm{H}^{+}$on BEA-33 d. $\mathrm{Pd}^{+} \mathrm{H}^{+}$on BEA-55. The same color coding as in Figure 5 . 


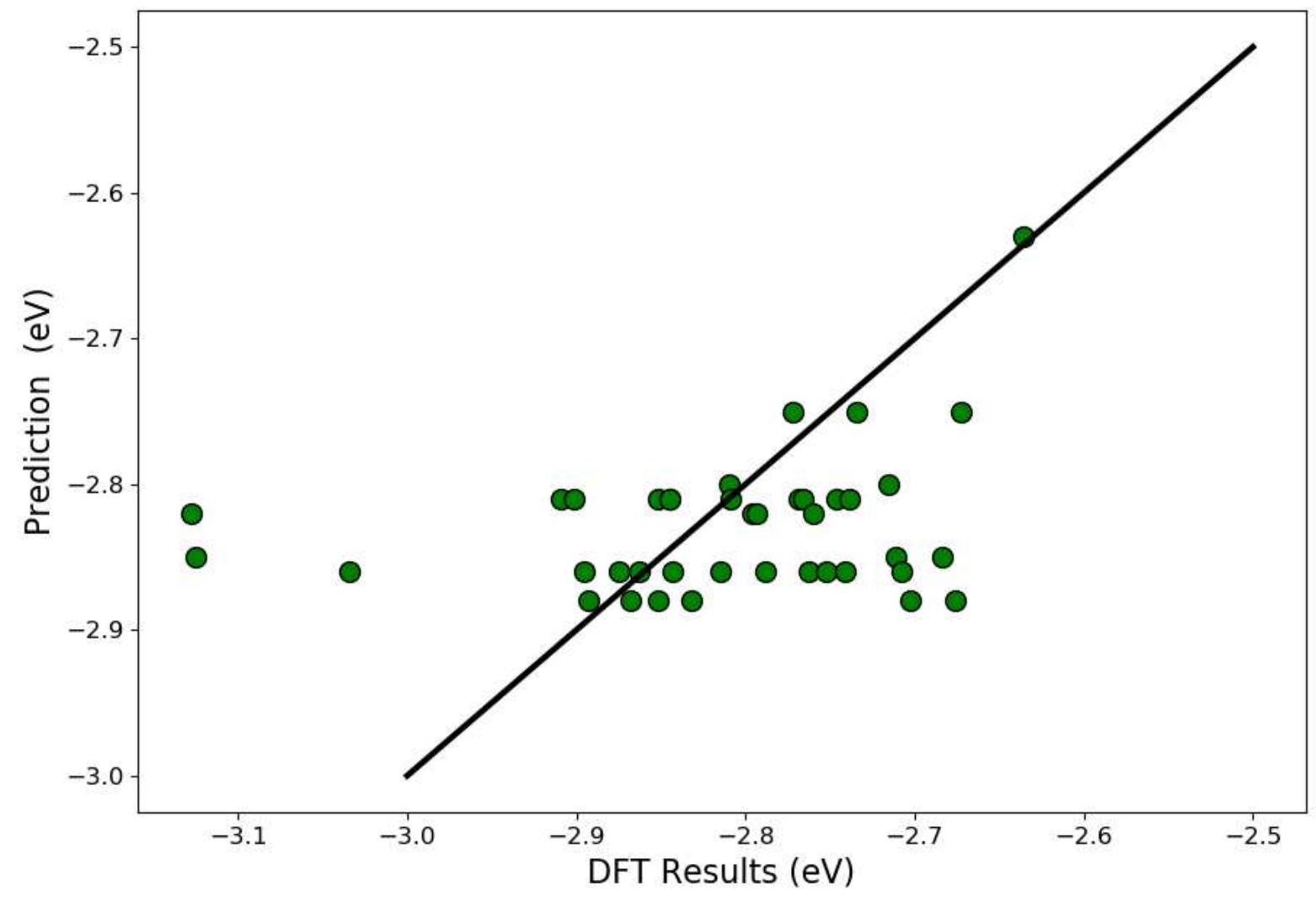

Figure S13: Parity plot of the calculated DFT energy on Al pairs (that do not share a MR) and the predicted energy based on the respective isolated $\mathrm{Al}$ site (the most stable of the two). All calculations were done on $\mathrm{BEA}$ with $\mathrm{Pd}^{+} \mathrm{H}^{+}$as the cation 
a.

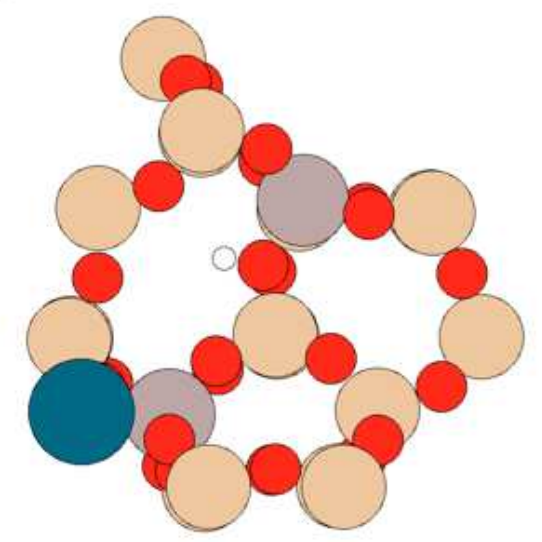

C.

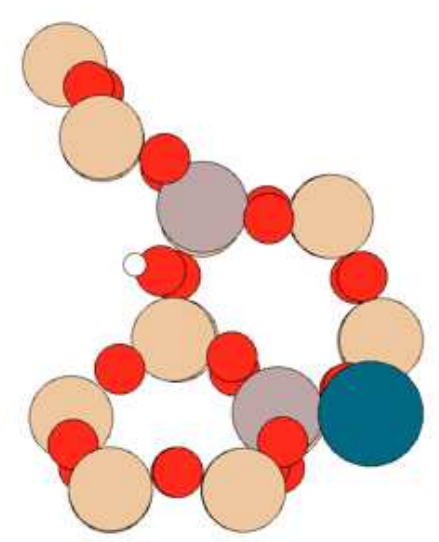

b.

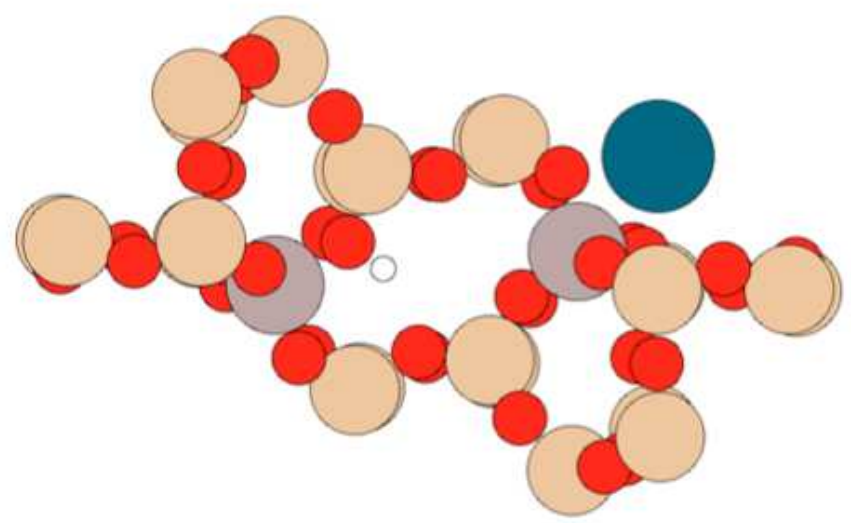

Figure S14: Image of the QM region on optimized BEA calculations a. BEA-51 $\left(\mathrm{Pd}^{+} \mathrm{H}^{+}\right)$b. BEA-78 $\left(\mathrm{Pd}^{+} \mathrm{H}^{+}\right)$c. BEA-52 $\left(\mathrm{Pd}^{+} \mathrm{H}^{+}\right)$. The same color coding as in Figure 5. 
Table S2: Difference in NO adsorption energy $\left(\Delta \mathrm{E}_{N O}\right)$ on $\mathrm{Pd}^{+} \mathrm{H}^{+}$in $\mathrm{CHA}$ when the two electrons (from $\mathrm{Pd}^{+}$and $\mathrm{NO}$ ) are paired and the two electrons are unpaired. Paired electrons are used as the reference $(0 \mathrm{eV})$

\begin{tabular}{c|c|c} 
Structure Name & Paired Electrons & Two Unpaired Electrons \\
\hline CHA-5 & 0 & 0.89 \\
CHA-8 & 0 & 0.82 \\
CHA-7 & 0 & 1.53 \\
\hline
\end{tabular}


a.

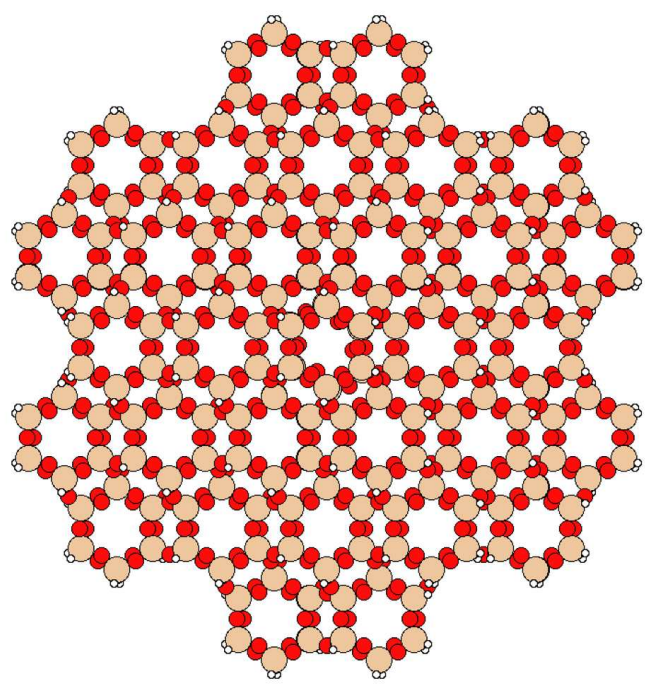

b.

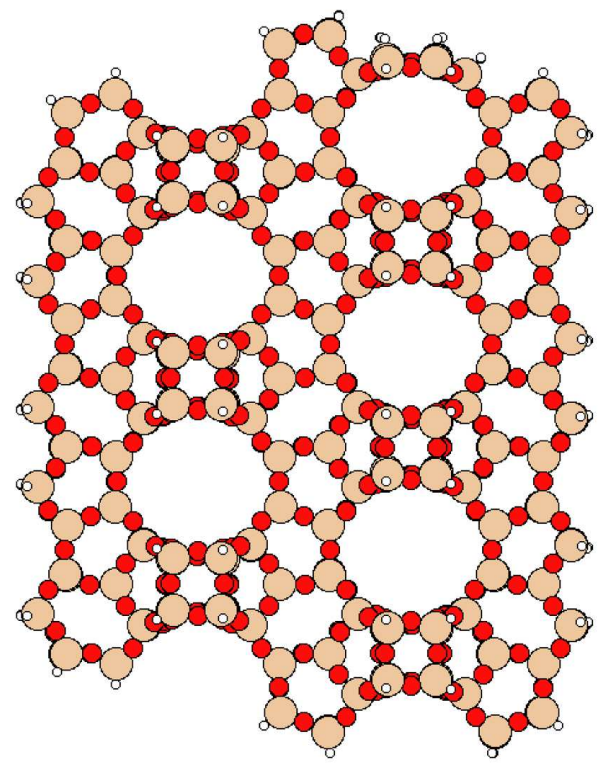

Figure S15: Cluster models of a. T696 CHA and b. T810 BEA. The same color coding as in Figure 5 


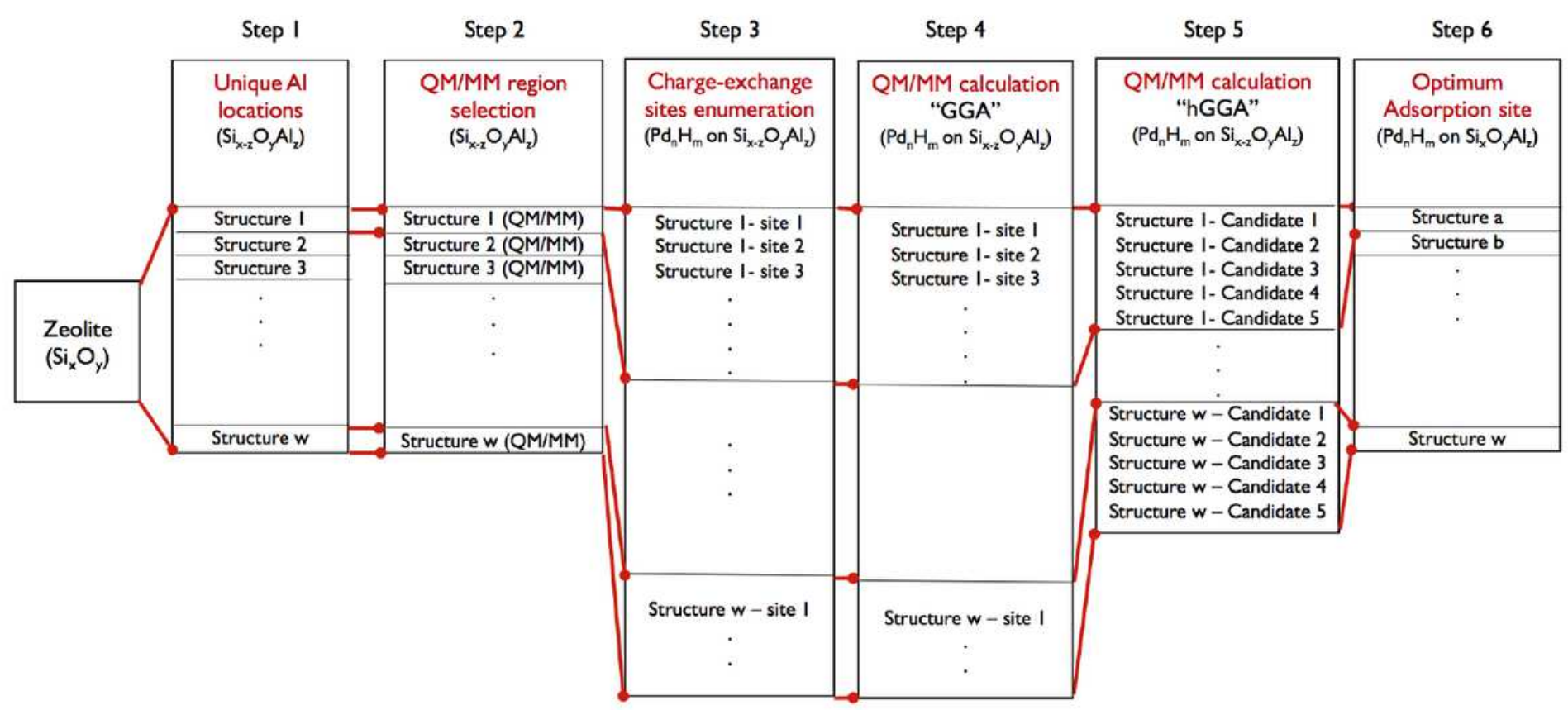

\section{Figure 1}

Please see manuscript PDF for full caption. 

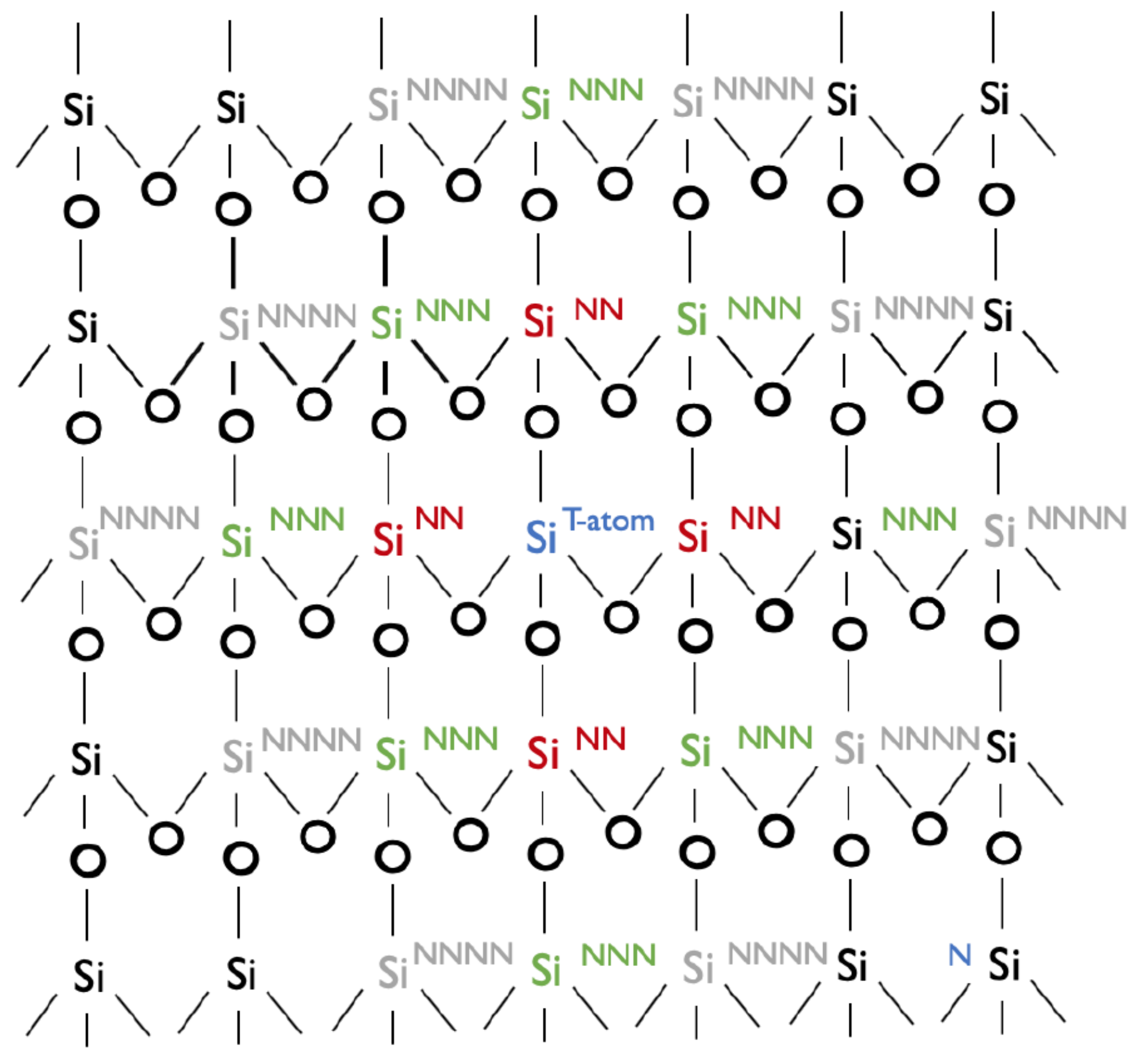

Figure 2

Please see manuscript PDF for full caption. 


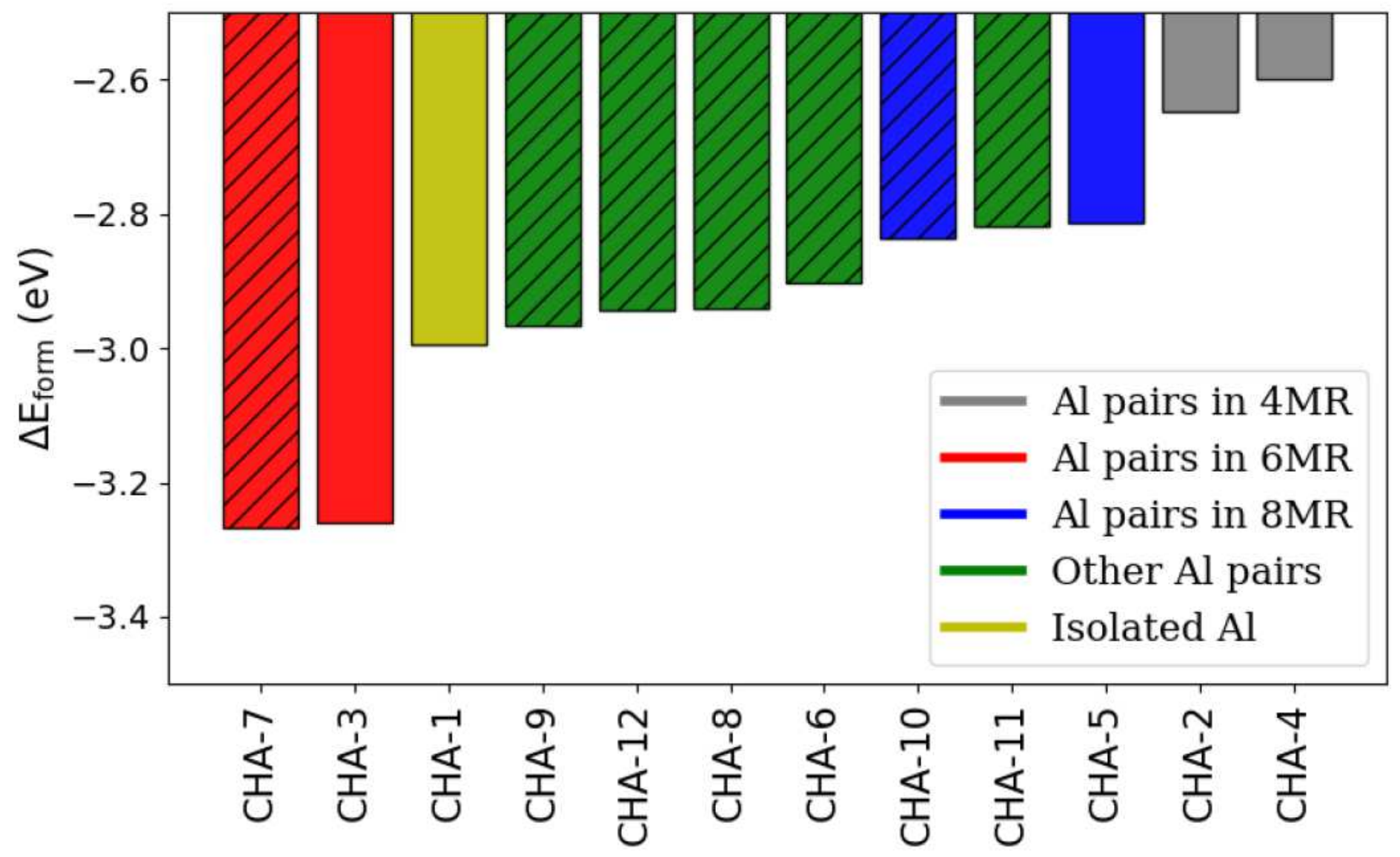

Figure 3

Please see manuscript PDF for full caption. 


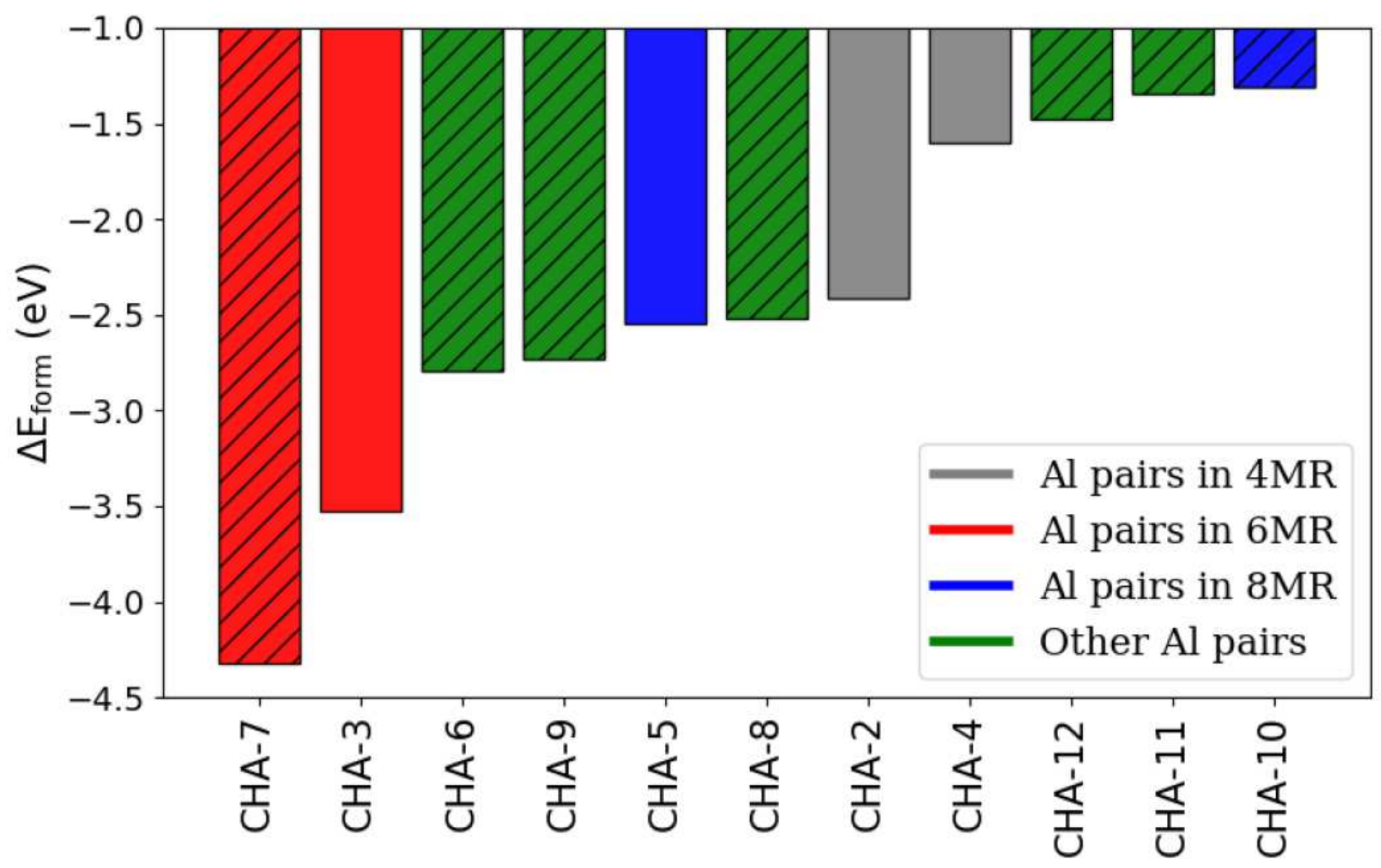

Figure 4

Please see manuscript PDF for full caption. 
a. $\mathrm{Pd}^{+2}$ on $\mathrm{CHA}-7$

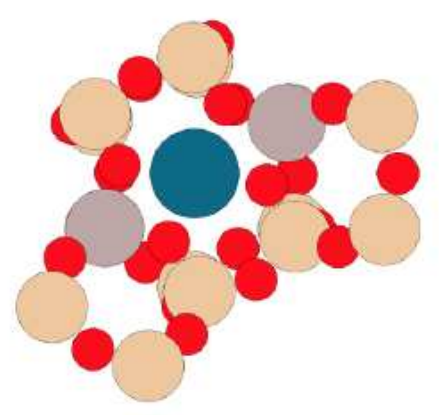

e. $\mathrm{Pd}^{+2}$ on $\mathrm{BEA}-45$

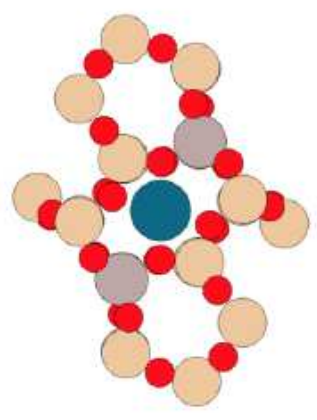

b. $\mathrm{Pd}^{+2}$ on $\mathrm{CHA}-3$

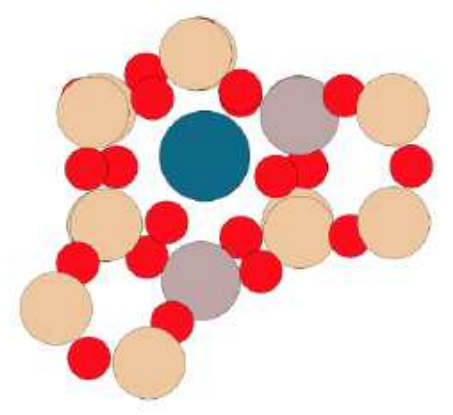

f. $\mathrm{Pd}^{+2}$ on BEA-4I

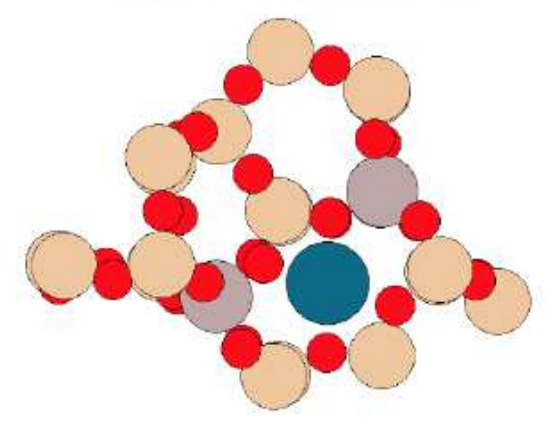

c. $\mathrm{Pd}^{+2}$ on BEA-65

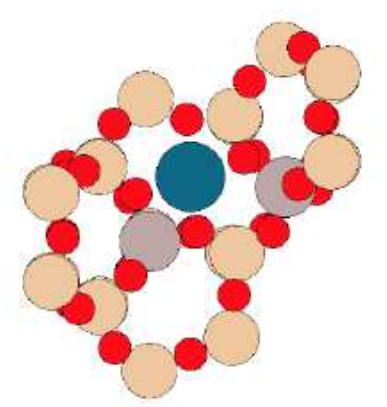

g. $\mathrm{Pd}^{+} \mathrm{H}^{+}$on $\mathrm{BEA}-65$

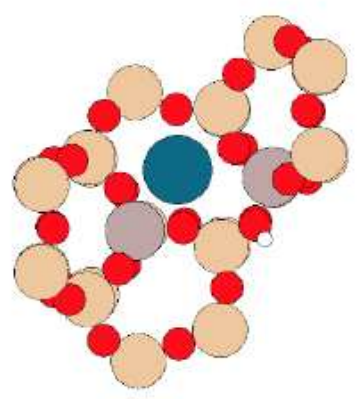

d. $\mathrm{Pd}^{+2}$ on BEA-80

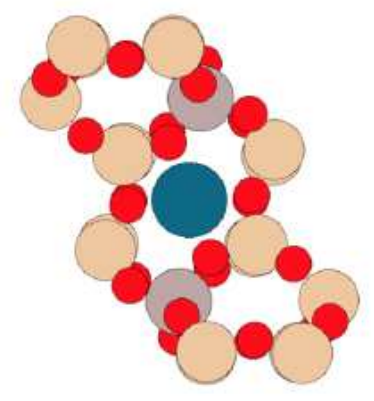

Figure 5

QM atoms of the optimized calculations. Color coding: red=Oxygen, white=Hydrogen, blue=Palladium and beige=Silicon

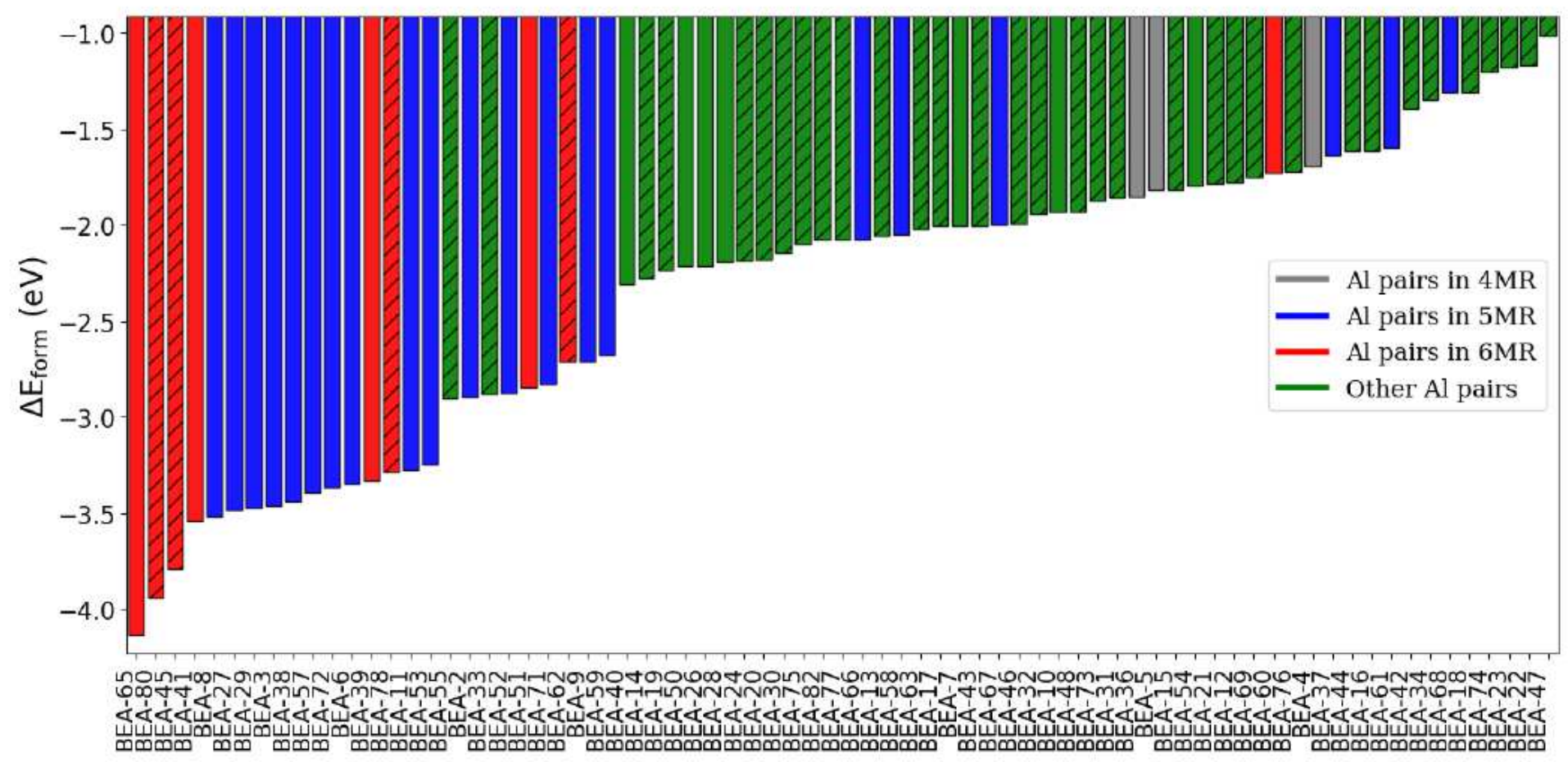

Figure 6 
Please see manuscript PDF for full caption.

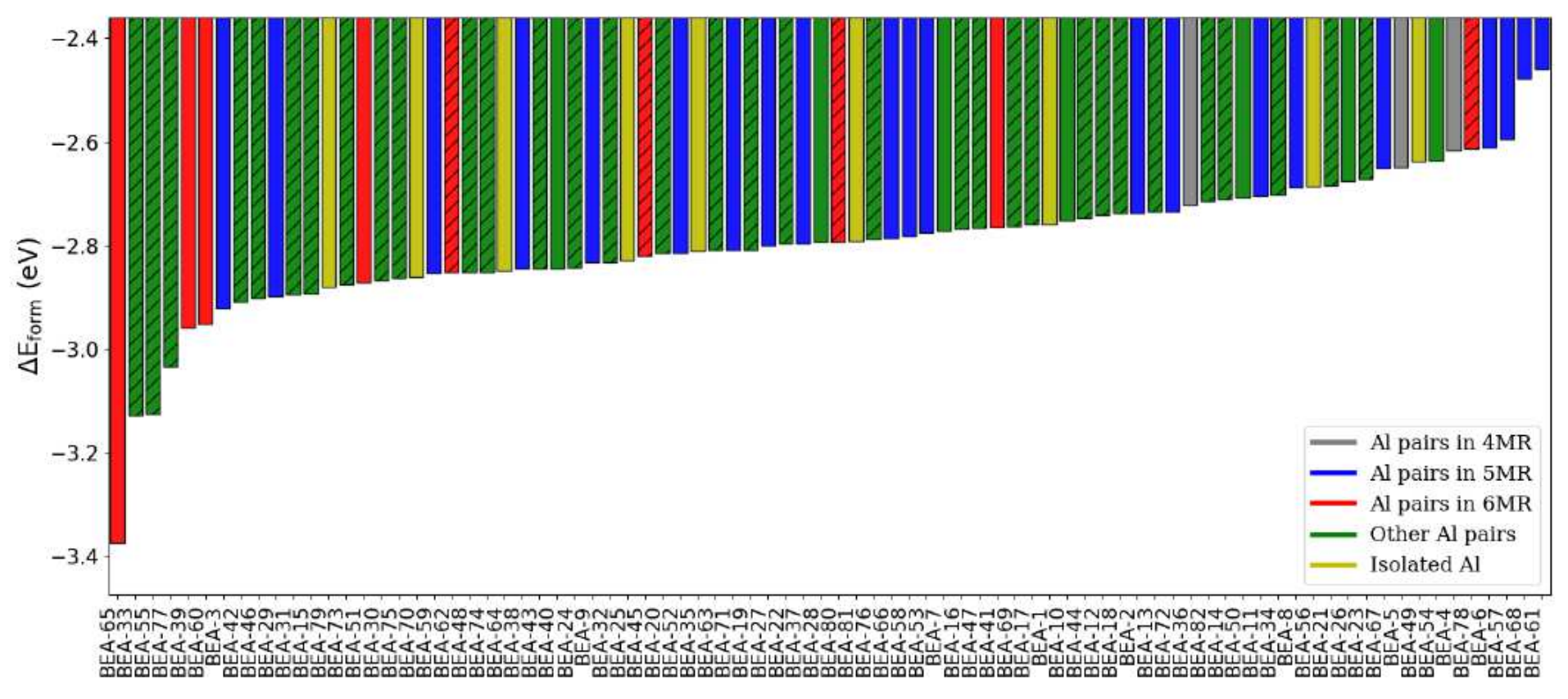

Figure 7

Please see manuscript PDF for full caption.

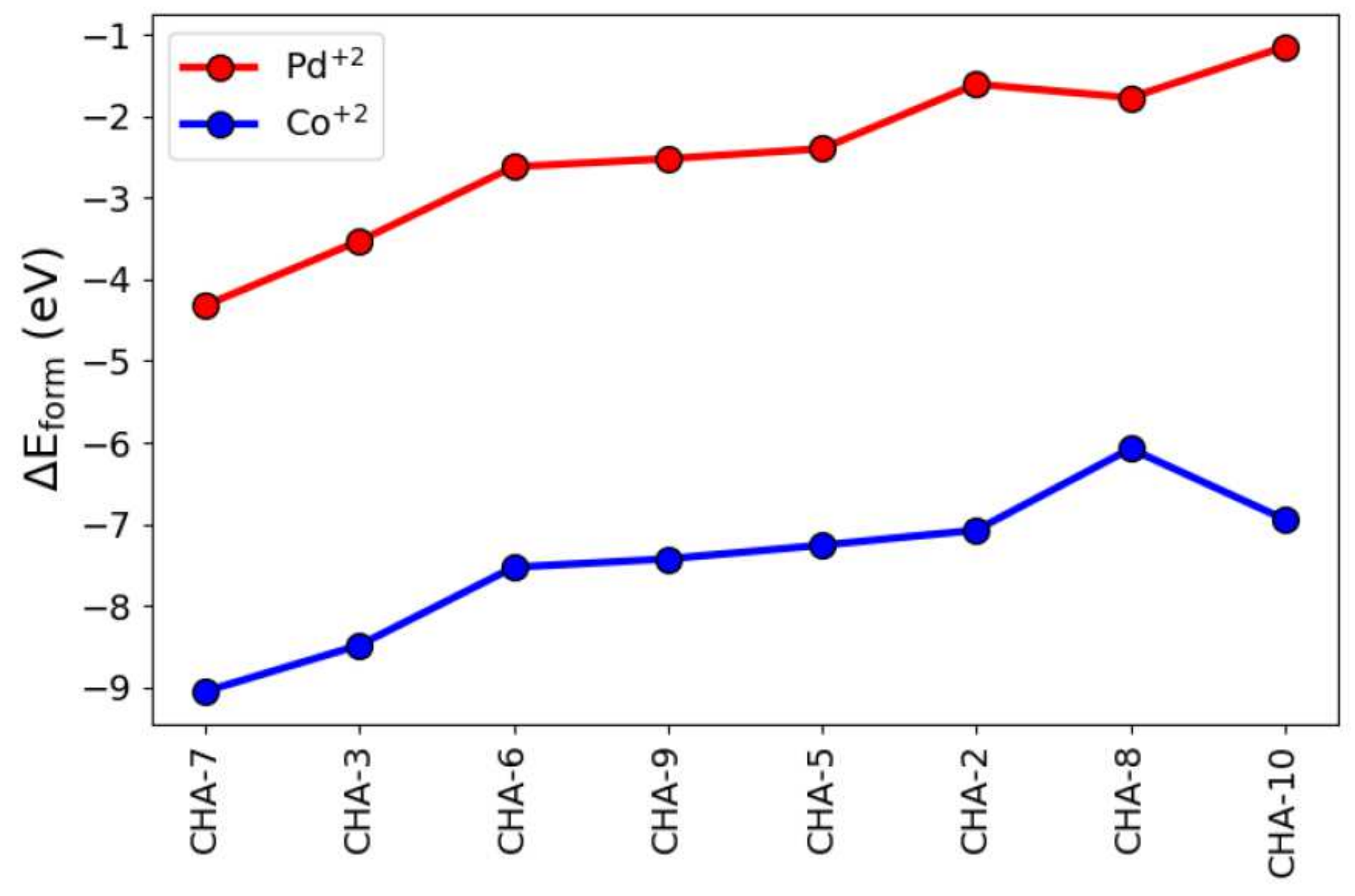


Figure 8

Please see manuscript PDF for full caption.

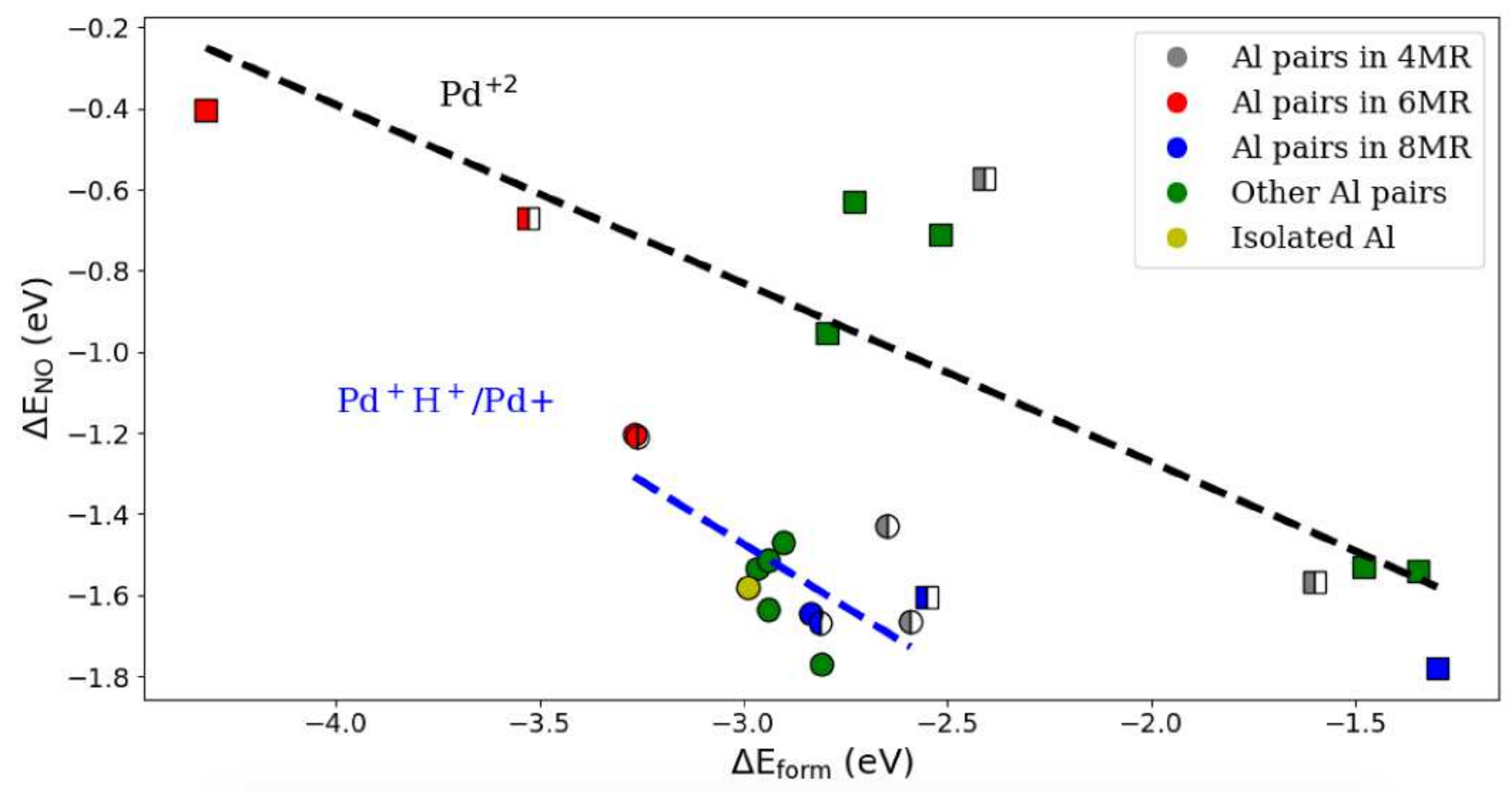

Figure 9

Please see manuscript PDF for full caption.

\section{Supplementary Files}

This is a list of supplementary files associated with this preprint. Click to download.

- SI.pdf 